\title{
CORRELAÇÃO DO MAGMATISMO DAS BACIAS DA MARGEM CONTINENTAL BRASILEIRA COM O DAS ÁREAS EMERSAS ADJACENTES
}

\author{
FERNANDO FLÁVIO MARQUES DE ALMEIDA*; CELSO DAL RÉ CARNEIRO* \\ \& ANA MARIA PIMENTEL MIZUSAKI $* * *$
}

\begin{abstract}
CORRELATION OF MAGMATISM OF THE BRAZILIAN MARGINAL BASINS WITH THE ADJACENT. EMERGED CONTINENTAL AREAS The available information on the Cretaceous-Tertiary magmatism in Brazilian marginal basins is synthesized, aiming at a comparison with similar events that affected the emerged adjacent areas. The Eocretaceous pre-Aptian basaltic volcanism is more common in the basins from Espírito Santo to the Sduth, where it can be correlated with dikes and lava flows of the Serra Geral Formation. It is also present in Northeast Brazil, at the southern part of the submerged Potiguar Basin. At the extreme south of Brazil, the presence of acid magmatism in the Paraná Basin allows one to suppose the existence of similar compositions in the poorly known Pelotas Basin. The quiescence of magmatism during Aptian-Albian time is a common characteristic of almost all Brazilian marginal basins, as well as in the emerged continental area, but rocks belonging to this age are present in the Ceará Basin and in the Cabo area (PE). Neocretaceous-Eocene magmatism of alkàline trend is present in the emerged region of the Cabo Frio Magmatic Lineament. Possibly it can be extended to the submerged margin. Eocene volcanism is very important at the Cabo Frio Platform and south of Campos Basin. The islands situated along the Santos BasirTs margin are composed by feldspathoid-bearing alkàline rocks, the emplacement of which is related to the Rio de Janeiro Lineament. The Tertiary volcanism in Northeast Brazil lasted until Miocene, in the Potiguar Basin and emerged region, but in South-Southeast Brazil it seems to have ceased after Eocene. The Fernando de Noronha Fracture Zone extended up to the coast, allowing the onset of Oligocene alkaline volcanism. The Remanche Fracture Zone extends up to the Ceará Basin and the São Luís Craton, and controls the acid magmatism observed in the Atlântico and Ceará highs. The Vitória-Trindade Fracture Zone also seems to extend to the continent, as suggested by the structures and basic dikes of the Fundão Suite. The basins situated between the Ceará State and the Marajó Island are amagmatic, as well as the Recôncavo Basin, in part because they have been installed on rigid crust of São Luís and São Francisco cratons. It is suggested that the faster continent withdrawal in the South as compared to the Northeast Brazil associated to different rift processes could have been the cause for cessation of volcanism only after the Miocene in the last region.
\end{abstract}

Keywords: Mesozoic-Cenozoic magmatism, continental margin, coastal region, tectono-magmatic activation, marginal basins, coastal basins, volcanism, magmatic lineaments, fracture zones

\begin{abstract}
RESUMO Sintetizam-se informações sobre o magmatismo cretáceo-terciário nas bacias da margem continental brasileira, comparando-o com o das áreas emersas adjacentes. No Eocretáceo pré-aptiano, o vulcanismo basáltico é o mais comum nas bacias do Espírito Santo para sul, correlacionando-se aos diques e derrames da Formação Serra Geral. Também está presente no Nordeste, na Bacia Potiguar submersa, correlato dos diques básicos, situados a sul dela. Na extremidade sul do Brasil, a presença de magmatismo ácido na Bacia do Paraná permite supor a existência de composições similares na base da Bacia de Pelotas, mas os estudos nessa região são ainda incipientes. No Aptiano-Albiano observa-se atenuação do magmatismo em quase todas as bacias marginais e no continente emerso, embora rochas dessa idade estejam presentes na Bacia do Ceará e na região do Cabo (Pernambuco). No Neocretáceo-Eoceno o magmatismo exibe caráter alcalino no Alinhamento Magmático de Cabo Frio, que possivelmente se estende à margem submersa. No Eoceno o vulcanismo é acentuado na Plataforma de Cabo Frio e sul da Bacia de Campos. Na borda W da Bacia de Santos, ilhas são constituídas de rochas alcalinas feldspatóidicas, relacionadas ao Alinhamento do Rio de Janeiro. No Terciário, o vulcanismo no Nordeste estendeu-se ao Mioceno, na Bacia Potiguar e na região emersa, porém no Sul-Sudeste parece ter cessado após o Eoceno. A Zona de Fratura Fernando de Noronha prolongou-se à costa, permitindo, no Oligoceno, penetração de magma alcalino associado a vulcanismo. A de Remanche atinge a Bacia do Ceará, adentrando o Craton de São Luís; apresenta magmatismo ácido nos altos Atlântico e do Ceará. A Zona de Fratura Vitória-Trindade também parece estender-se ao continente, tal como evidenciado pelas estruturas e diques básicos da suíte Fundão. As bacias existentes entre a Ilha do Marajó e a Bacia do Ceará são amagmáticas, do mesmo modo que a Bacia do Recôncavo, em parte por se situarem sobre crosta rígida, respectivamente dos cratons de São Luís e do São Francisco. Sugere-se que o mais rápido afastamento dos continentes na margem sul que a nordeste, aliado a diferentes processos de rifteamento, tenha sido a causa da cessação do vulcanismo somente após o Mioceno nesta última região.
\end{abstract}

Palavras-chaves: magmatismo mesozóico-cenozóico, margem continental, região costeira, ativação tectono-tagmática, bacias marginais, bacias costeiras, vulcanismo, alinhamentos magmáticos, zonas de fratura

\begin{abstract}
INTRODUÇÃO O processo de rifteamento que, do Neojurássico ao Eocretáceo, deu origem ao Oceano Atlântico Sul, foi acompanhado e sucedido por inúmeros eventos magmáticos nas bacias da margem continental, nos altos que as separam, bem como no continente emerso adjacente. Em território brasileiro, salvo exceções, os produtos desse episódio são relativamente bem conhecidos, quanto à sua petrografia, idade e condições geológicas, mas não tanto quanto à sua natureza petroquímica. $\mathrm{Na}$ área marginal submersa, somente com o advento de perfurações para hidrocarbonetos é que tais produtos tornaram-se conhecidos, por meio da análise de testemunhos de sondagem. Apesar do grande
\end{abstract}

número destas sondagens, executadas desde a década de 70 , esses conhecimentos são mais limitados devido à própria natureza do material e, em que pese a maior atenção da PETROBRAS sobre o tema nos últimos anos (Mizusaki 1986, 1989, Mizusaki et al. 1992,1994, dentre outros), os dados são pouco divulgados.

No presente trabalho, sem perder de vista as limitações acima apontadas, procura-se assinalar as relações espaciais e temporais das rochas magmáticas que são conhecidas em dois ambientes tectônicos: o das bacias da margem continental, emersas e submersas, e o das áreas próximas a elas, no interior do continente, em geral constituídas de rochas pré-cambrianas

* Alameda Franca 432, Apto. 9, CEP 01422-000, São Paulo, SP

** Instituto de Geociências, Universidade Estadual de Campinas - UNICAMP, Caixa Postal 6152, CEP 13083-970, Campinas, SP, Fax (019)-239-1562

*** Instituto de Geociências, Universidade Federal do Rio Grande do Sul, Av. Bento Gonçalves 9500, CEP 91509-900, Porto Alegre, RS 
expostas (Fig. 1) ou sob coberturas pliocênicas e/ou quaternárias. Eventuais correlações possibilitam determinar com mais precisão os sucessivos regimes tectônicos pós-permianos que se implantaram na borda leste da América do Sul, pois os registros magmáticos têm se mostrado indicadores confiáveis para tal análise.

Verifica-se que o magmatismo ocorre esparsamente distribuído, ou é muito limitado em certas áreas, o que pode ser atribuído ao tipo de rifteamento e a outros fatores aqui não abordados. Episódios vulcânicos estão bem representados na região sul-sudeste, no Nordeste oriental e no Amapá mas são pouco conhecidos para o norte da Bacia do Espírito Santo e a oeste da Bacia do Ceará até pelo menos a região da Ilha de Marajó. É frequente, mas não plena, a correspondência entre o magmatismo presente nas bacias costeiras e altos marginais que as separam, com aquele encontrado nas áreas continentais adjacentes.

O presente trabalho reúne informações, antes dispersas na literatura acessível, acerca da distribuição e idade dessas manifestações, sem abordar o quimismo de detalhe do magmatismo ou suas fontes mantélicas. Tem assim, o caráter de síntese de conhecimentos, da qual decorrem algumas conclusões e sugestões de pesquisa complementar.

GEOLOGIA Asmus \& Guazelli (1981) aceitaram a suposição de diversos autores por eles citados de que do Permiano terminal ao Triássico teria existido soerguimento dômico intenso na porção sudeste do Brasil, onde acarretou

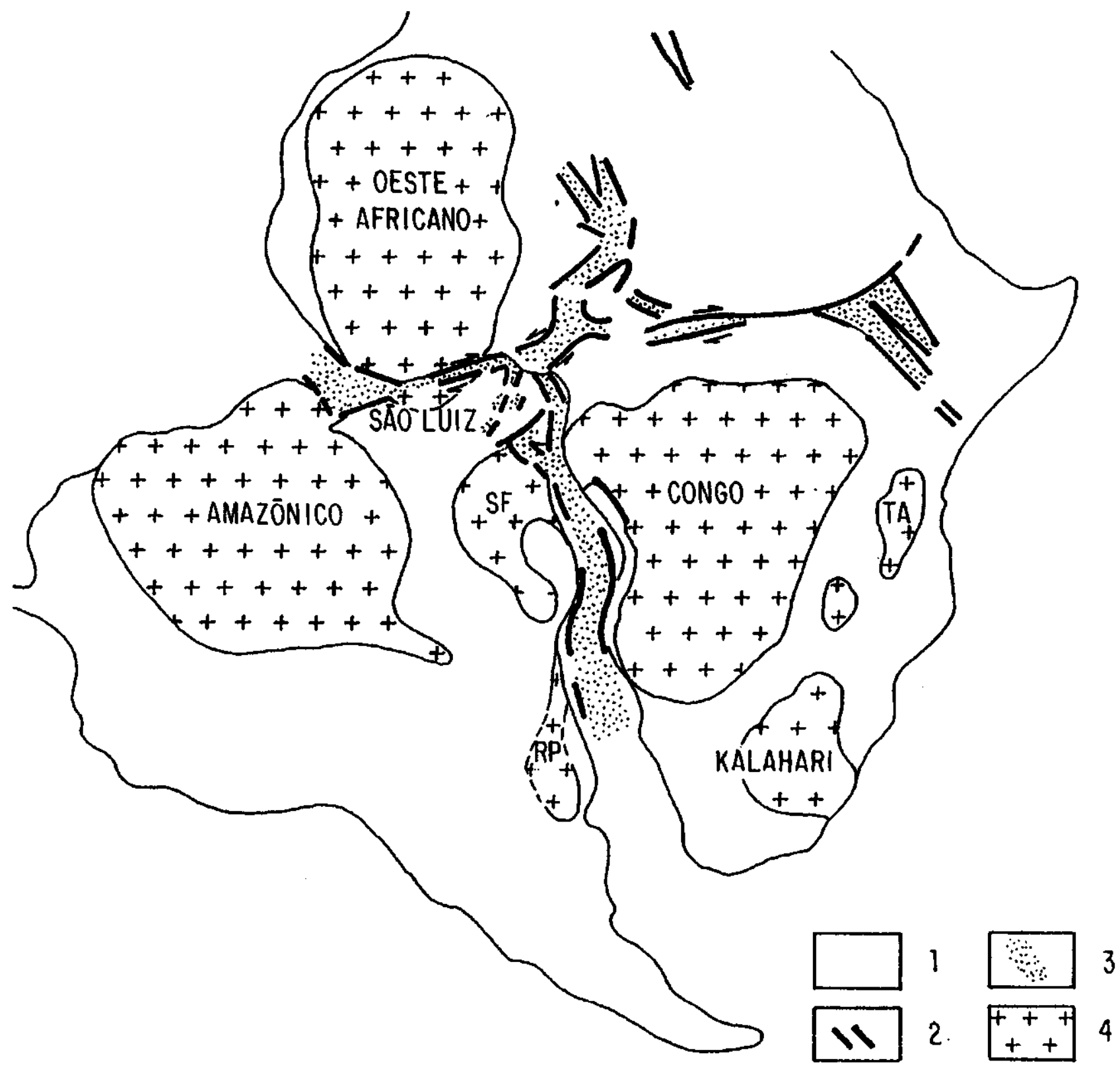

Figura 1 - Mapa de reconstrução do Gondwana Ocidental, com destaque para: (1) áreas continentais, (2) zonas falhadas, (3) áreas submetidas a rifteamento Juro-Cretáceo e (4) crátons antigos. Baseado em Fairhead (1988), Unternehe et al. (1988), Guiraud \& Maurin (1992), Hoffinan (1991) e Zalán et al. (1990)

Figure 1 - Reconstruction of Western Gondwana: (1) continental areas, (2) the main fault zones, (3) the Jurassic-Cretaceous rifted areas and (4) the ancient cratons. Map based on Fairhead (1988), Unternehe et al (1988), Guiraud \& Maurin (1992), Hoffman (1991) and Zalán et al. (1990) 
importante manifestação magmática, segundo o modelo de Gass (1973), por eles modificado. Estes fenómenos estariam relacionados a processos estruturais e magmáticos resultantes de perturbações térmicas no manto. Uma zona de magma aproximadamente tabular causaria o soerguimento da litosfera e injeção de magma litosférico na crosta continental. Lembram esses mesmos autores que a homogeneização isotópica verificada por Thomaz-Filho et al. (1976), aproximadamente há $180 \mathrm{Ma}$, em sedimentos da Bacia do Paraná, teria resultado dessa anomalia térmica. Ao domeamento seguiu-se o estágio rift-valley, com a formação de riftes do tipo plataforma (Milanovsky 1972), subtipo arco-vulcânico. O estágio rift (mais comumente traduzido para rifte) foi assinalado por estruturas extensionais, como falhamentos normais e abatimentos da crosta, do que resultaram as bacias do sudeste e do sul da margem continental brasileira (Fig. 2). Tal identidade genética filia-se à semelhança entre o magmatismo da área continental emersa (Formação Serra Geral) e o embasamento basáltico neojurássico a eocretáceo das bacias de Santos, Campos, Espírito Santo, o Alto Estrutural de Florianópolis e o Alto de Cabo Frio (Fig. 2).

Na Formação Serra Geral predominam basaltos toleiíticos, porém com variações químicas marcantes. Constituem derrames sobrepostos, às vezes, separados por arenitos cretáceos. No sul da Bacia do Paraná, embora localmente, alguns derrames chegam a apresentar composições riolíticas e riodacíticas (Melfi et al. 1988). Há soleiras e grandes quantidades de diques, destacando-se os que obedecem à orientação geral NW, associados aos enxames do Arco de Ponta Grossa, e os orientados segundo ENE, subparalelos às estruturas pré-cambrianas do Arco da Serra do Mar, na região de Santos, que se tornam escassos desde Campos até o Espírito Santo. Intrusões alcalinas são comuns.

Figueiredo \& Gabaglia (1986) e Gabaglia \& Figueiredo (1990), sumariando os resultados de trabalhos realizados por um grupo de geólogos da PETROBRAS S.A., classificaram as bacias sedimentares brasileiras adotando a classificação de Kingston et al. (1983a, b). Apresentaram um quadro muito ilustrativo quanto à tectônica, origem marinha ou lacustre e continental, bem como tectônica modificadora das bacias. Incluíram não só as bacias marginais, mas também as internas ao país. Sendo específica à pesquisa de petróleo, essa classificação pouco contribui ao conhecimento do magmatismo das bacias.

Para o estabelecimento de vínculos entre magmatismo, etapas de rifteamento crustal e evolução tectônica das bacias é necessário conhecer de modo tão completo quanto possível a distribuição e as variações composicionais dos registros disponíveis. Na borda leste do continente sul-americano, a evolução guarda analogia, em linhas gerais, com padrões reconhecidos nas partes oeste e central da África. Binks \& Fairhead (1992) mostraram que o rifteamento intracontinental precede cada etapa de ruptura continental. Embora muitas bacias tenham se aprofundado devido à subsidência termal, $\mathrm{o}$ rifteamento ativo aproximadamente cessa quando o material da crosta oceânica começa a ser colocado ao longo da linha de separação crustal associada àquela fase de ruptura (Binks \& Fairhead 1992). É também aceito que tal distribuição do rifteamento aproveita zonas crustais mais fracas do Ciclo Pan-Africano, na África, e do Brasiliano, na América do Sul. O magmatismo intracontinental está, portanto, subordinado a esses parâmetros gerais de evolução tectônica, sendo importante conhecer sua distribuição para avaliar o grau de fidelidade dos controles já identificados.

Bacia de Pelotas A Bacia de Pelotas é a mais meridional das nossas bacias marginais. Sua porção brasileira estende-se por $210000 \mathrm{~km}^{2}$ até a lâmina d'água de $2000 \mathrm{~m}$, com cerca de $40000 \mathrm{~km}^{2}$ emersos, entre os paralelos $28^{\circ} \mathrm{e} 34^{\circ}$ sul. Seu limite norte, com a Bacia de Santos é situado no Alto de Florianópolis, enquanto o limite sul é marcado pela região lindeira com o Uruguai (Dias et al 1994).

Os conhecimentos atuais a respeito dessa área foram obtidos através dos dados resultantes da perfuração de cinco poços na sua porção submersa e de oito na porção emersa, bem como a partir das interpretações de linhas sísmicas.

Na porção submersa da Bacia de Pelotas, prováveis derrames basálticos, inclinados para o mar (seaward dipping reflections), apresentam-se recobertos por grande espessura de sedimentos aptiano-albianos e terciários (Fontana 1987 apud Souza 1993). A melhor datação pelo método K/Ar destes derrames provém de um testemunho do poço 1-RSS-3 com 124 8,6 Ma (Mizusaki 1987 [rel. int.] apud Dias et al. 1994). São denominados de Formação Imbituba e presume-se que sejam essencialmente síncronos aos derrames da Formação Serra Geral, da Bacia do Paraná.

Na porção emersa, justaposta à da Bacia de Pelotas, destaca-se o Arco de Rio Grande (Sanford \& Lange 1960) ou de São Gabriel, que expõe o embasamento pré-cambriano, contornado em grande parte pelos sedimentos paleozóicos. Orienta-se a NW, em posição aproximadamente normal às estruturas do embasamento. Uns poucos diques de diabásio nele também se dispõem. Um conjunto de intrusões alcalinas está presente no município de Piratini (Pinto et al. 1975, Maciel Filho \& Sartori 1979) datadas de cerca de 80 Ma (Cordani et al 1974). Até o momento, rochas semelhantes a estas, tanto em idade como composição, não foram encontradas na parte submersa da bacia.

Alto Estrutural de Florianópolis Esse alto estrutural separa as bacias de Pelotas e Santos. E capeado por expressivo volume de rochas básicas de caráter extrusivo que prosseguem, com espessura considerável, para o interior do continente, após faixa de rochas pré-cambrianas e paleozóicas. Pode-se esperar que os basaltos atravessados por perfurações na plataforma continental (poços 1-SCS-2e 1-SCS-3 da PETROBRAS), por sua natureza petrográfica e provável idade cretácea inferior, possam ser correlacionados com a Formação Serra Geral. O traquiandesito do poço 1-SCS-1, com megacristais de sanidina, datado pelo método $\mathrm{Ar} / \mathrm{Ar}$ em $113 \pm \mathrm{O}, 1 \mathrm{Ma}$, constitui um evento vulcânico distinto, denominado de Formação Curumim (Dias et al 1994). Segundo Asmus (apud Alves 1981), estaria relacionado com o Lineamento de Florianópolis. Tal unidade constitui-se, ao que se supõe, de feições magmáticas de orientação E-W entre os paralelos $38^{\circ}$ e $44^{\circ} \mathrm{W}$. Kumar (apud Alves 1981) supõe que o lineamento se prolongue para oeste pela chamada Dorsal de São Paulo, porém, a partir de $42^{\circ} \mathrm{W}$, encontra-se recoberto por sedimentos.

A oeste, na direção do Lineamento de Florianópolis, ocorrem no continente, não longe da costa, as intrusões alcalinas de Anitápolis (Carraro et al 1967) e de Lajes (Scheibe 1978). $\mathrm{Na}$ intrusão de Anitápolis, datada de $129 \mathrm{Ma}(\mathrm{K} / \mathrm{Ar}$, Amaral et al 1967), associam-se ijolitos, melteijitos, urtitos e nefelina sienitos, além de carbonatitos locais. Na intrusão de Lajes, datada por Scheibe et al (1985) em $82 \pm 6 \mathrm{Ma}(\mathrm{K} / \mathrm{Ar})$, ocorrem nefelina sienitos, fonólitos, foiaitos e rochas uítrabásicas alcalinas. Devem-se acrescentar ainda as pequenas intrusões de Quarenta (D'Elboux et al 1982), inferidas por Guazzelli \& Carvalho (1981) como possível prolongamento, continente adentro, do Lineamento de Florianópolis. Nesta região, nenhuma perfuração, até o momento, atingiu rochas tipicamente alcalinas.

Bacia de Santos A Bacia de Santos situa-se na costa sudeste brasileira, entre os paralelos $23^{\circ}$ e $28^{\circ}$ sul e ocupa cerca de $275000 \mathrm{~km}^{2}$ até a cota batimétrica de $2000 \mathrm{~m}$. O Alto de Cabo Frio é a feição que a separa da Bacia de Campos. As 
rochas sedimentares e ígneas depositadas nesta bacia não afloram e o conhecimento de sua estratigrafia tem por base a análise de 78 poços e linhas sísmicas, tanto pela PETROBRAS como por companhias de risco (Pereira \& Feijó 1994).
A presença de basaltos continentais eocretáceos foi comprovada pelo poço l-SPS-4 (idade K/Ar de $121 \pm 11 \mathrm{Ma}$ ) que os perfurou. Foram inicialmente denominados de Formacão Cananéia (Ojeda \& Aranha 1980). No entanto, o termo foi

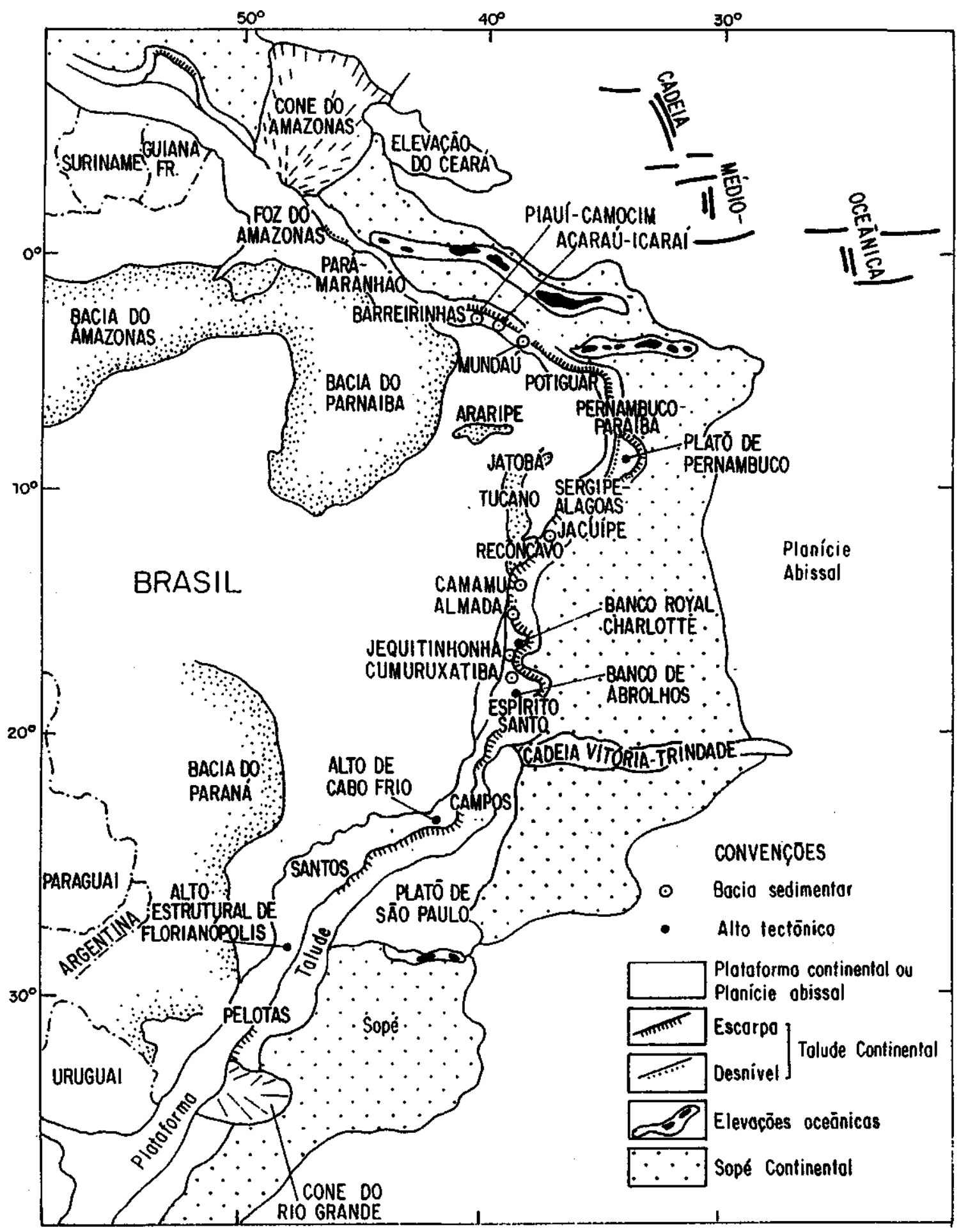

Figura 2 - Mapa de localização das principais feições tectono-estruturais da costa brasileira. Bacias sedimentares: Bacia de Pelotas, Bacia de Santos, Bacia de Campos, Bacia do Espírito Santo, Bacia de Bahia Sul, Bacia do Recôncavo-Tucano, Bacia Sergipe-Alagoas, Bacia Pernambuco-Paraiba, Bacia Potiguar, Bacia do Ceará (representada pelas sub-bacias de Mundaú, Acaraú-Icaraí e Piaui-Camocim), Bacia de Barreirinhas, Bacia do Pará-Maranhão, Bacia da Foz do Amazonas. Altos: Alto Estrutural de Florianópolis, Alto de Cabo Frio e Platô de Pernambuco

Figure 2 - Situation map of principal tectonic-structural features of the Brazilian coast. Sedirnentary Basins: Pelotas Basin, Santos Basin, Campos Basin, Espírito Santo Basin, Bahia Sul Basin, Recôncavo-Tucano Basin, Sergipe-Alagoas Basin, Pernambuco-Paraíba Basin, Potiguar Basin, Ceará Basin (as represented by Mundaú, Acaraú-Icaraí and Piaú-Camocim sub-basins), Barreirinhas Basin, Pará-Maranhão Basin, Amazon Mouth Basin. Tectonic Highs: Florianópolis Structural Platform, Cabo Frio High and Pernambuco Plateau 
substituído por Formação Camboriú (Pereira \& Feijó 1994), uma vez que Suguio \& Petri (1973) já haviam denominado de Formação Cananéia os sedimentos pleistocênicos da planície costeira de São Paulo. A Formação Camboriú é recoberta discordantemente pela Formação Guaratiba (Ojeda \& Césero 1973). Pesquisas geofísicas mostram a grande extensão desses basaltos no assoalho da bacia (Fig. 3a).

No litoral a NE da Ilha de São Sebastião, na região entre Ubatuba e Caraguatatuba, Damasceno (1966) encontrou uma centena de diques de diabásio, olivina diabásio e lamprófiros, orientados a NE. Refere seis datações $\mathrm{K} / \mathrm{Ar}$, com valores entre 124,5 e 131,1 Ma. Um segundo período de atividade magmática manifestou-se na área continental adjacente à bacia, bem como nesta. Na bacia, suas rochas têm sido datadas do Cretáceo Superior (e.g. poço l-RJS-81, com $90 \pm 6 \mathrm{Ma}$ ) e parecem constituir derrames de composição toieiítica/sub-alcalina. Em ilhas ao largo da costa de São Paulo, na plataforma continental, também ocorrem rochas neocretáceas intrusivas, datadas pelo método K/Ar (Amaral et al. 1967), como Cananéia (82 Ma), no sul do estado, São Sebastião (81 Ma), Montão de Trigo (80 Ma) e Vitória.

Alguns resultados de datação, embora de forma esparsa, têm mostrado a presença de um magmatismo eocênico quase sempre com tendência levemente alcalina. Sua natureza e forma de ocorrência ainda não se encontram bem definidas. Em terra, ocorrem derrames de ankaramito em Itaboraí (Klein \& Valença 1984) e na Bacia de Volta Redonda, para os quais Riccomini (1989) acusou 43,8 Ma e 41,7 Ma. Intrusão de tinguaíto (51 Ma) ocorre em Cabo Frio (Amaral et al. 1967).

$\mathrm{Na}$ área continental emersa, em São Paulo, Minas Gerais e Rio de Janeiro, corpos alcalinos constituem um alinhamento há muito conhecido. Marsh (1973) atribui-lhes idades (baseado em Amaral 1967) entre 83 e 51 Ma, mas entre elas inclui as neocretáceas das ilhas Montão do Trigo e São Sebastião, na plataforma continental. Desta última ilha Hennies \& Hasui (1968) dataram um traquito que acusou 54,5 Ma, idade que consideraram suspeita, pois a rocha exibe feições de devitrificação. Marsh (1973) supôs que tal alinhamento fosse extensão ao continente de uma fratura oceânica que alcançaria a crista Médio-Atlântica, equiparando-a a uma falha transformante. Sadowski \& Dias Neto (1971) definiram o Alinhamento Sismo-Tectônico de Cabo Frio como uma deflexão da costa associada ao limite norte da Bacia de Santos. Estes autores efetuaram a reconstrução da posição dos continentes por rotação inversa até a junção das placas, definindo as posições das trajetórias das respectivas rotações a cada intervalo de tempo geológico. A trajetória ou círculo mínimo referente à posição do pólo entre 84 e $49 \mathrm{Ma}$ coincide com apreciável precisão com o alinhamento de rochas alcalinas de Cabo Frio a Poços de Caldas. Prolongando-se, para oeste, o arco de círculo obtido por Sadowski \& Dias Neto (1971), verifica-se (Almeida 1991) que na região de Jaboticabal (SP) ele passa junto a rochas efusivas de analcita fonólitos intercaladas no Grupo Bauru (Coimbra et al. 1981). Gomes \& Valarelli (1970) descreveram a rocha dessa região como um tinguaíto, que seria um dos condutos das lavas alcalinas. Embora esteja incluída em rochas neocretáceas, a rocha acusou idade de $54 \mathrm{Ma}$, pelo método $\mathrm{K} / \mathrm{Ar}$, o que requer verificação.

Em uma faixa de aproximadamente $60 \mathrm{~km}$ de largura, tendo o arco de círculo mínimo de 84 a 49 Ma como mediana, acham-se contidos pelo menos 26 corpos de rochas alcalinas, das quais três contêm rochas efusivas. Prolongando-se esse arco em direção ao mar, verifica-se que ele passa pelo isolado banco submarino Almirante Saldanha, que corresponde a edifício vulcânico arrasado pela erosão marinha, cuja natureza litológica é desconhecida. Teria assim o arco uma extensão da ordem de $1150 \mathrm{~km}$. O intervalo conhecido de idade de todas essas rochas varia entre 87 e 43 Ma, ou seja, entre Santoni-
ano-Campaniano até Eoceno, estando as idades mais jovens dispostas junto ao litoral. São rochas de caráter predominantemente félsico, com destaque para nefelina sienito, pulaskito, foiaíto, fonólito, tinguaíto e traquito. Faz-se notar a presença de leucita e pseudo-leucita em várias delas, assim como algumas rochas máficas e alcalino-ultramáficas (ankaratritos). Vieira et al. (1987) assinalam em mapa gravimétrico residual uma importante anomalia na plataforma que consideram poder representar uma intrusão de rocha alcalina como as que afloram no continente. Essa anomalia, próxima à falha-charneira de Campos e a $90 \mathrm{~km}$ a ENE de Cabo Frio, acha-se incluída na referida faixa de $60 \mathrm{~km}$ de largura.

Pereira et al. (1986) mostram que na porção submersa da bacia os eventos de vulcanismo básico repetiram-se até o Eoceno (57 Ma).

As datações ora conhecidas para as alcalinas dessa faixa não justificam considerá-las como resultantes do deslocamento da placa sobre um ponto quente no manto, pois não há sequência cronológica entre elas. É certo que as idades radiométricas dessas rochas precisam ser refinadas antes que tal hipótese possa ser totalmente descartada.

Verifica-se, do exposto, haver apreciável correlação, tanto em idades como em arranjo estrutural, entre o magmatismo da Bacia de Santos e o da área continental emersa.

Altp de Cabo Frio O Alto de Cabo Frio, que separa as bacias de Campos e Santos, apresenta grande incidência de rochas magmáticas. Mohriak et al, (1990) reconhecem em poços exploratórios da região de Cabo Frio, uma espessa sequência vulcano-sedimentar em que derrames basálticos se intercalam com rochas vulcanoclásticas e sedimentares. Assim, para esta região, com base em dados sísmicos, petrográfi$\cos$, químicos e radiométricos, propõem a sua subdivisão em três sequências relativamente bem definidas. Na Sequência I, eocretácea pré-aptiana, os basaltos representam a formação Cabiúras (Dias et al. 1994) e são datados pelo método K/Ar entre 120 e 130 Ma. Podem ser correlacionados com a Formação Camboriú da Bacia de Santos. A Sequência II é pouco representativa e também constituída por basaltos. Vincula-se ao Campaniano-Turoniano (80-90 Ma), graças à sua posição estratigráfica e datações pelo método K/Ar. A Sequência III, mais comum nesta região, contém basaltos, diabásios e rochas vulcanoclásticas, representando vulcanismo subaquoso de conduto central, associado a sedimentos representativos de períodos de quiescência (Mizusaki \& Mohriak 1993). As idades radiométricas K/Ar apontam valor médio entre 40 e 50 $\mathrm{Ma}$, o que caracteriza um importante evento vulcânico do Paleoceno Superior/Eoceno na região do Alto de Cabo Frio. É perfeita, pois, a correlação entre o magmatismo do Alto de Cabo Frio e o da área continental emersa, em São Paulo e Rio de Janeiro. Vale notar que, no Oligoceno, tanto quanto ora se sabe, parece ter cessado toda a atividade magmática no sul-sudeste do Brasil e, supostamente, também na margem continental vizinha.

Bacia de Campos A Bacia de Campos situa-se na costa norte do estado do Rio de Janeiro e sul do estado do Espírito Santo. Seu limite norte com a Bacia do Espírito Santo é o Alto de Vitória e o limite sul, com a Bacia de Santos, corresponde ao Alto de Cabo Frio. Nos últimos 23 anos foram aí perfurados mais de 1000 poços que, juntamente com extensa malha sísmica, levantamentos gravimétricos e magnetométricos, permitiram detalhado conhecimento geológico (Rangel et al 1994).

O embasamento econômico da Bacia de Campos é formado por basaltos toleíiticos intercalados com rochas vulcanoclásticas e rochas sedimentares (Mizusaki 1986) que constituem a Formação Cabiúnas (Dias et al. 1994). Idades K/Ar dos basaltos Cabiúnas, obtidas por Thomaz-Filho (1981, 1984), 


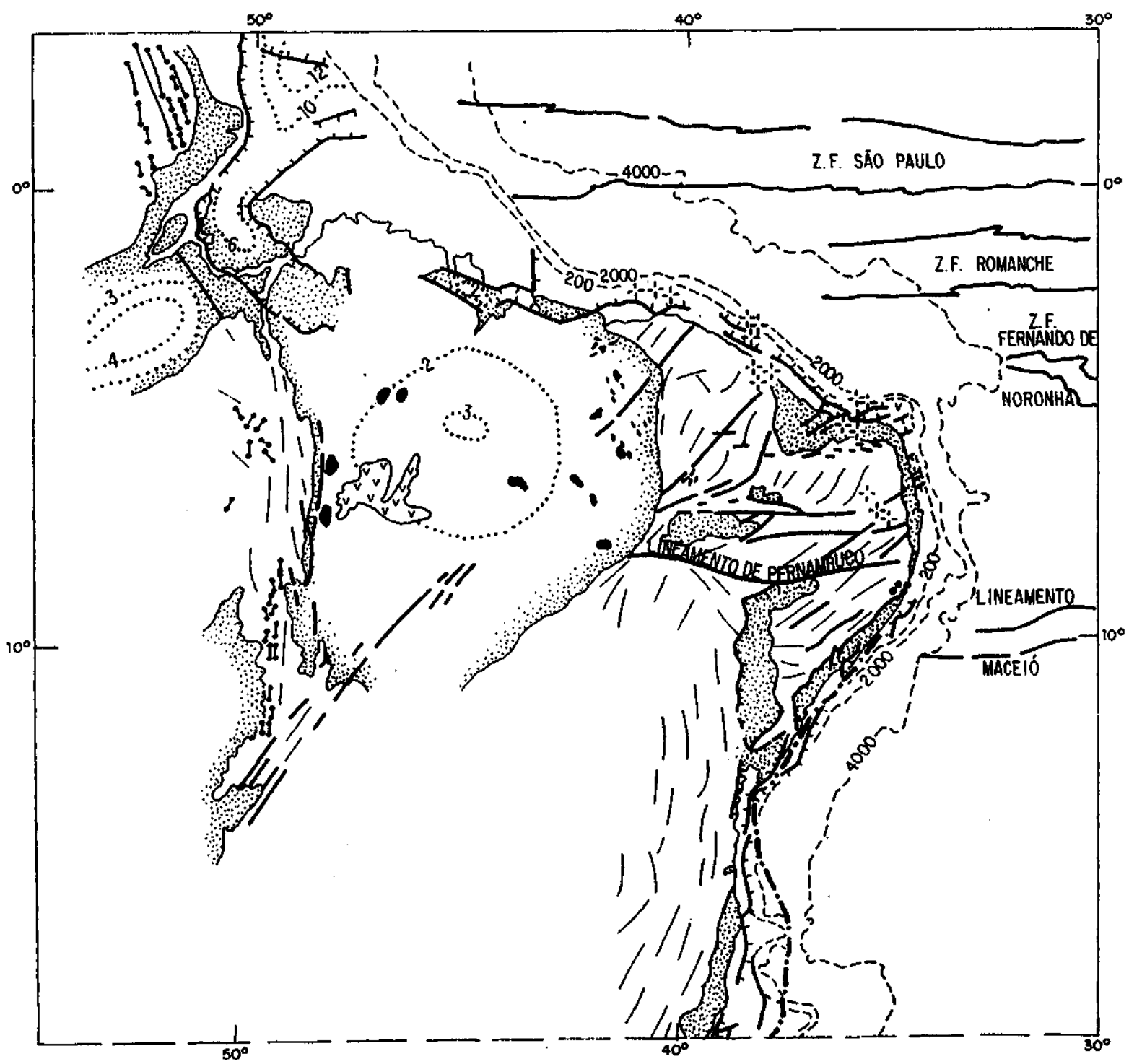

Figura $3 a$ - Localização de ocorrências vizinhas à costa setentrional do Brasil. Convenções indicadas na figura 3 b): (1) cota batimétrica (m); (2) contato geológico ou limite do continente; (3) isópacas (km); (4) limite externo da zona de sal em subsuperficie; (5) zona defratura ou falhamento, (6) falha normal; (7) alinhamento magmático; (8) dique do Cretáceo Inferior; (9) dique do Permo-Triássico a Jurássico Inferior; (10) orientação das estruturas no embasamento; (11) bacia sedimentar; (12) rochas ígneas terciárias; (13) rochas alcalinas e álcali-cálcicas; (14) basalto do Cretáceo Inferior na região costeira sul-sudeste, em subsuperficie; (15) basalto do Cretáceo Inferior no Banco de Abrolhos, em subsuperficie; (16) basaltos na Bacia do Paraná. Mapa compilado de Almeida (1986), Almeida (1991), Almeida et al. (1986), Almeida et al. (1988), Alves (1981), Asmus \& Guazzelli (1981), Carneiro et al. (1988), Carvalho \& Francisconi (1981), Gorini (1981), Riccomini et al (1987)

Figure 3a - General situation map of occurrences close to the northern Brazilian coast. Legend as show in figure 3 b): (1) bathimetric contour (m); (2) geological contact or continent boundary; (3) isopachs $(\mathrm{km})$; (4) external boundary of the subsurface salt zone; (5) fracture zone or regional fault, (6) normal fault; (7) magmatic allignment; (8) Lower Cretaceous dike; (9) Permian-Triassic to Lower Jurassic dike; (10) basement structural trend; (1 1) sedimentary basin; (12) igneous Tertiary rocks; (13) alkalyne and alkaline-calcic rocks; (14) Lower Cretaceous subsurface basalts of the SSE coastal region; (15) Lower Cretaceous buried basalts of Abrolhos Bank; (16) basalts of Paraná Basin. Compiled from Almeida (1986), Almeida (1991), Almeida et al. (1986), Almeida et al (1988), Alves (1981), Asmus \& Guazzelli (1981), Carneiro et al (1988), Carvalho \& Francisconi (1981), Gorini (1981) and Riccomini et al (1987)

citadas por Mizusaki (1986) indicam valores entre $122 \pm 5 \mathrm{e}$ 1344 Ma, ou seja, Neocomiano (baseado em AAPG 1983).

Para a Formação Cabiúnas, Mizusaki et al. (1988) propõem modelo de vulcanismo físsural com fases subaéreas e fases subaquosas rasas que interagem tanto com processos vulcanoclásticos como processos sedimentares. Estudo petrológico desses basaltos realizado por Mizusaki et al. (1992) e sua posterior comparação com os da Formação Serra Geral (Bacia do Paraná), de idade semelhante (132-134 Ma por Ar/Ar, segundo Renne et al 1992), revelou composição química muito similar.

O segundo evento magmático nesta região provavelmente ocorreu no Cretáceo superior comprovado pela datação do gabro do poço l-RJS-66, com idade K/Ar de $81 \pm 5 \mathrm{Ma}$. As idades nesta faixa são esparsas e concentram-se principalmente na porção centro-sul da bacia.

Do Paleoceno ao Eoceno inferior/médio, manifestou-se novo episódio vulcânico muito bem registrado na área limite 


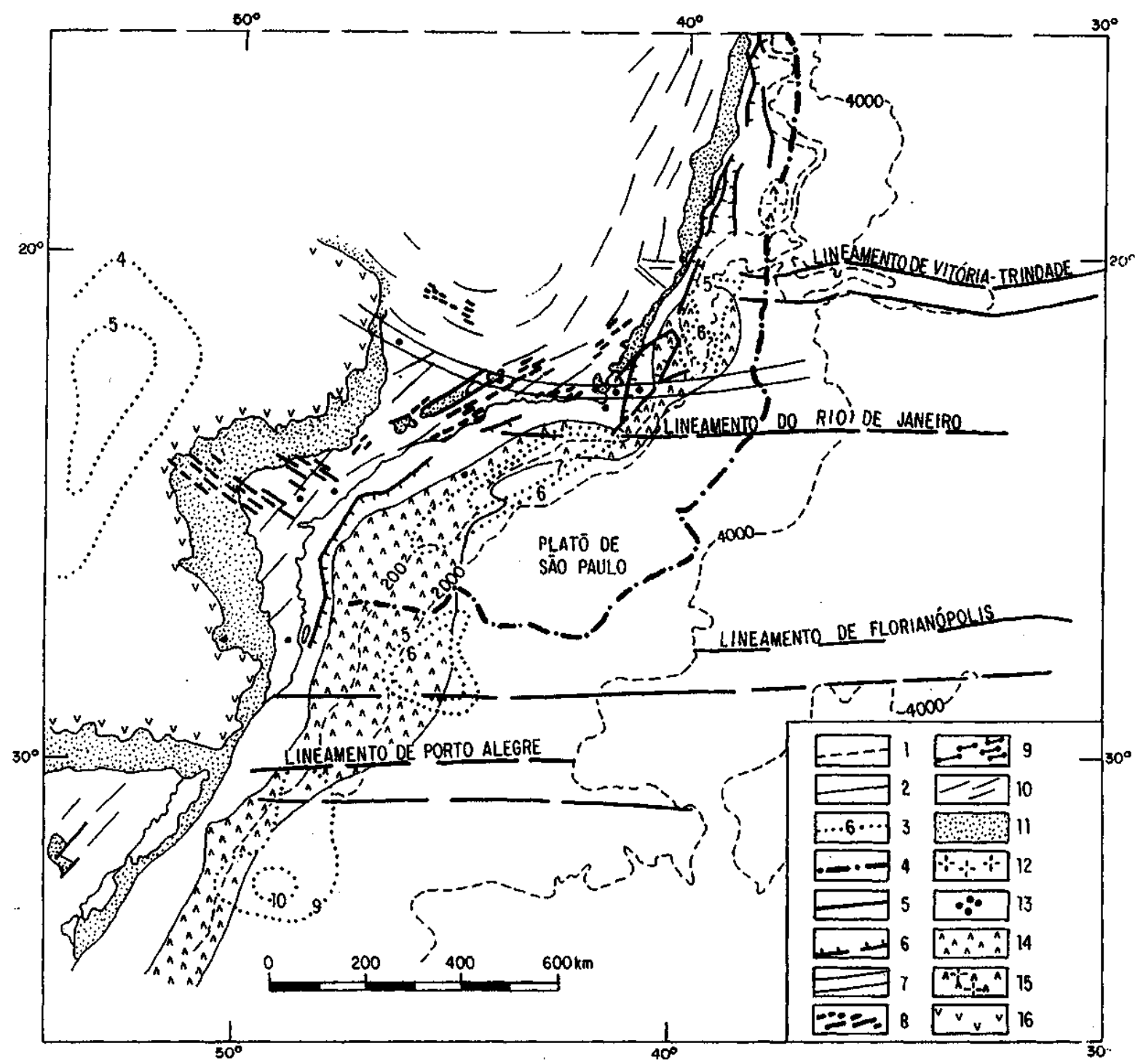

Figura 3 b - Localização de ocorrências vizinhas à costa meridional do Brasil.

Figure 3b-General situation map of occurrences dose to the northern Brazilian coast.

com a Bacia de Santos. São basaltos, diabásios e rochas vulcanoclásticas relacionadas a vulcanismo de conduto central e de composição levemente alcalina.

\section{Bacias do Espírito Santo, Mucuri e Cumuruxatiba}

Estas bacias abrangem quase $300500 \mathrm{~km}^{2}$, sendo que 250000 $\mathrm{km}^{2}$ encontram-se imersos. O limite norte, com a bacia do Jequitinhonha, é o banco vulcânico de Royal-Charlotte. O limite sul, com a Bacia de Campos, corresponde ao Alto de Vitória (Vieira et al 1994).

Nestas bacias (figs. 2 e 3) reconhecem-se dois episódios vulcânicos marcantes, o primeiro no Cretáceo inferior (Formação Cabiúnas) e o segundo, mais recente, no Paleoceno/Eoceno, denominado de Formação Abrolhos (Vieira et al. 1994).

As rochas ígneas básicas da Formação Cabiúnas ocorrem principalmente na porção terrestre da Bacia do Espírito Santo, sob a forma de derrames de basalto de composição toleiítica eventualmente associados com paleossolos. É provável que esse vulcanismo tenha boa continuidade na plataforma continental pois as rochas vulcânicas do poço l-ESS-18, aí situado, mostram idade de $132 \pm 3 \mathrm{Ma}$. A confirmação extensiva deste evento até o momento não foi obtida, pois a maioria dos poços perfurados na plataforma não atingiu a seção do Cretáceo inferior (Conceição et al. 1994).

A Formação Abrolhos, representativa do segundo evento, é caracterizada por uma associação litológica complexa, englobando rochas ígneas básicas de composição toleiítica a alcalina, vulcanoclásticas e eventuais intercalações de rochas sedimentares. Trata-se de um vulcanismo de conduto central em ambiente marinho e acumulado sobre plataforma continental estreita. Sua área de maior ocorrência é na porção submersa destas bacias, incluindo-se aí o Banco de Abrolhos. A Formação Abrolhos tem idade K/Ar entre 37 e 59 Ma (Mizusaki et al. 1994)

Nesta região, mais a norte, observa-se ainda o banco Royal Charlotte, no qual não se conhecem até agora rochas magmáticas. Supõe-se, no entanto, por dados geofísicos, que tenha estrutura semelhante ao Banco de Abrolhos.

A rocha vulcânica atingida pelo poço l-BAS-15, na Bacia de Cumuruxatiba porém nas proximidades de Royal Charlotte, forneceu excelente idade $\mathrm{K} / \mathrm{Ar}$ de $28 \pm 0,4 \mathrm{Ma}$. Este fato pode sugerir a eventual ocorrência de vulcanismo oligocênico 
nesta bacia. A confirmação deste evento, no entanto, deverá ser feita com base em número maior de determinações radiométricas, não obtidas até o momento (Conceição et al. 1994).

A cadeia vulcânica Vitória-Trindade orienta-se a lesteoeste, em direção à Bacia do Espírito Santo. É um conjunto de montes submarinos, guyots e, em seu extremo oriental, situam-se as ilhas de Trindade e Martim Vaz, formadas de produtos vulcânicos alcalinos (Almeida 1960,1961). Cordani (1970) obteve valores (K/Ar) de 2,9 e 2,3 Ma para a primeira e 86 e 61 Ma para a vizinha Martim Vaz, valores estes que considerou incertos.

Não se conhecem provas da extensão desse lineamento no continente emerso. Referem Guazelli \& Carvalho (1981) que, nas vizinhanças de Vitória, imagens de satélite indicam lineamentos a leste-oeste, que se estendem a $100 \mathrm{~km}$ para o interior do continente. Ocorre na faixa cataclástica proveniente do extremo norte da Bacia de Campos, conhecida como Vitória-Ecoporanga. Suas rochas pré-cambrianas foram retrabalhadas no Neoproterozóico. Orienta-se a NNW-SSE e tem mais de 200 km de extensão; aloja feixe de diques de diabásio que constitui a chamada Suíte Fundão (Silva et al 1983). Sial et al. (1987) indicam idade aproximada (K/Ar) de $170 \mathrm{Ma}$ (Jurássico médio), para essas rochas. Tal idade coloca um problema. Por estar na projeção da cadeia Vitória-Trindade para o interior da área continental emersa, poderia ser geneticamente ligada a ela, mas sua idade e a orientação quase perpendicular à direção da cadeia são desfavoráveis a essa interpretação.

Bacia de Sergipe-Alagoas Santos \& Castro (1992) e Cainelli (1992) mostram que algumas manifestações magmáticas podem ser reconhecidas em registros sísmicos, nas porções mais distais da bacia Sergipe-Alagoas, já sob lâmina de água com mais de $2000 \mathrm{~m}$ de profundidade.

Essas estruturas são interpretadas como corpos rochosos compactos e coniformes com poucos quilômetros quadrados de área, interpostos às rochas sedimentares, sugerindo a construção de montes vulcânicos. Para Feijó (1994), a verdadeira natureza e idade destas rochas são desconhecidas, mas os truncamentos e deformações provocados nos refletores sísmicos permitem atribuir-lhes provável idade turoniana. Intrusões localizadas, também identificadas nesta região, têm sido relacionadas ao magmatismo eocênico

Platô de Pernambuco Entre o Alto provavelmente vulcânico do Banco Royal Charlotte e o Platô de Pernambuco (figs. 2 e 3b), na projeção em direção ao mar, do Lineamento de Pernambuco, os únicos registros comprovados, até o momento, de rochas magmáticas, são as desse platô. Do mesmo modo, na área continental emersa adjacente, não há rochas magmáticas relacionadas à ativação mesozóica, senão na região do Cabo de Santo Agostinho (Gorini \& Bryan 1976, Ponte \& Asmus 1976). Infere-se que a origem das rochas basálticas da porção leste do Platô de Pernambuco (Guazelli et al 1977, apud Guazelli \& Carvalho 1981) esteja ligada à Província Magmática do Cabo. Nesta província associa-se ainda o magmatismo cretáceo predominantemente constituído de rochas vulcânicas de afinidade alcalina transicional a alcali-cálcica, que ocorre na forma de pequenos derrames, diques, plugs e soleiras, denominado Formação Ipojuca (Amaral \& Menor 1979).

A Formação Ipojuca é provavelmente explicada pela reativação do Lineamento continental de Pernambuco e sua extensão ao Platô de Pernambuco e, por este, ao Lineamento homónimo, no oceano.

O granito alcalino do Cabo, pertencente a esta província, já foi datado diversas vezes, pelos métodos $\mathrm{K} / \mathrm{Ar}$ e $\mathrm{Rb} / \mathrm{Sr}$ (Gava et al. 1983). Suas amostras fornecem isócrona de cerca de 103 Ma (Albiano) enquanto Asmus \& Baisch (1983) indicam idades de 90-130 Ma para o complexo basálticogranítico.

Na porção interna do Platô de Pernambuco, a leste da cidade de Recife, foi identificado por interpretação sísmica um gráben contendo quatro unidades estratigráficas distintas. $\mathrm{Na}$ unidade inferior, perfuração da PETROBRAS atingiu um quartzo-latito datado de $103 \pm 4$ Ma (Feijó, 1994, inclui este dado já na bacia de Pernambuco-Paraíba).

No trecho entre a foz do Jequitinhonha e o sistema de falhas de Itaporanga d'Ajuda, a fragmentação do continente realizou-se em área do Cráton do São Francisco, o que poderia explicar (Asmus 1982) a ausência de magmatismo nestas bacias marginais, que devem ter como embasamento as estru turas desse cráton, não reativadas pela orogenia brasiliana. E de se observar que, também na área continental adjacente às bacias, tal magmatismo aparentemente não existe. É sabido que toda a área do Cráton do São Francisco é muito pobre em manifestações magmáticas relacionadas à ativação mesozóica. Próximo à sua borda, mas fora dela, fraturas orientadas a NE-SW, em rochas afetadas pelo evento Brasiliano encaixam diques de diabásio, datados de $105 \mathrm{Ma}$, pouco distantes da borda sudeste da Bacia de Jatobá (Magnavita 1990 apud Change et al. 1992).

Bacia de Pernambuco-Paraíba A porção submersa da Bacia Pernambuco-Paraíba corresponde a uma estreita faixa de cerca de $9000 \mathrm{~km}^{2}$ situada ao longo do litoral dos estados de Pernambuco e Paraíba, estendendo-se por $24000 \mathrm{~km}^{2}$ pela plataforma continental. Limita-se a norte pelo Alto de Touros com a Bacia Potiguar e a sul pelo Alto de Maragogi com a Bacia de Alagoas (Feijó 1994).

O conhecimento estratigráfico da Bacia de PernambucoParaíba foi obtido a partir dos estudos de superfície realizados na sua faixa de afloramentos. Na plataforma continental, somente foram perfurados dois poços pela PETROBRAS. As seções sísmicas nesta região permitem a individualização de sequências deposicionais similares às que são descritas nas demais bacias costeiras, porém com espessura muito reduzida.

A bacia Pernambuco-Paraíba mostra algumas evidências sísmicas da presença de rochas vulcânicas em águas profundas.

Bacia Potiguar A Bacia Potiguar ocupa peno de $60000 \mathrm{~km}^{2}$, sendo aproximadamente $40 \%$ emersos, no extremo leste da margem equatorial brasileira, entre os meridianos $35^{\circ}$ e $38^{\circ} \mathrm{W}$. Seu limite noroeste é no Alto de Fortaleza, com a Bacia do Ceará, e o limite leste, com a Bacia Pernambuco-Paraíba, se faz pelo Alto de Touros. Segundo Araripe \& Feijó (1994), até o presente foram perfurados 4000 poços na Bacia Potiguar (92\% em terra), e registrados cerca de 115000 km de seções sísmicas de reflexão (78\% no mar).

$\mathrm{Na}$ Bacia Potiguar são reconhecidos três episódios vulcânicos, datados pelo método K/Ar e individualizados em três formações.

A Formação Rio Ceará-Mirim (Gomes et al. 1981, Martins et al 1989) exposta junto à borda sul da porção terrestre da bacia, é o evento mais antigo, juro-cretáceo, constituindo feixes de diques de olivina diabásio orientados na direção E-W. Estendem-se desde a região costeira a norte de Natal, até o Rio Jaguaribe. As datações radiométricas obtidas em amostras de superfície e de subsuperficie apontam para idades entre 120 e $140 \mathrm{Ma}$, o que equivale aproximadamente às idades Valanginiano a Aptiano. Araripe \& Feijó (1994) consideram que esta formação equivale à Formação Cabiúnas, das bacias de Campos e do Espírito Santo (Dias et al 1994)

No Alto de Touros, já na porção submersa da bacia, foi perfurada uma rocha com textura diabásica e idade ra- 
diométrica de $130 \pm 15$ Ma, correlacionada com a Formação Rio Ceará-Mirim.

A Formação Cuó ocorre na serra do mesmo nome, na porção sul da bacia, sob forma de diques de diabásio. As idades radiométricas obtidas indicam um valor médio de $83 \pm 6 \mathrm{Ma}$, ou Santoniano-Campaniano.

Nos campos petrolíferos de Ubarana e Agulhas, a NE da cidade de Macau, na parte submersa da bacia, ocorrem derrames de olivina basalto datados estratigraficamente do Oligoceno e Mioceno, constituindo a Formação Macau (Mayer 1974). Idades radiométricas obtidas pelo método K/Ar indicam idades entre 29 e $45 \mathrm{Ma}$ (Eoceno/Oligoceno) (Mizusaki 1989). Tal como os derrames vizinhos, na parte emersa da bacia, sua ocorrência é restrita à cidade de Macau. $\mathrm{O}$ Alinhamento Macau-Queimadas (Almeida et al. 1988) é uma faixa orientada a N-S, que inclui as ocorrências acima referidas e se estende ao interior do estado da Paraíba, até Queimadas (Sial 1976a). Ali ocorrem vários plugs, necks e diques de diabásio, olivina basalto e ankaratrito (Sial 1976b), radiometricamente datados entre o Eoceno e o Mioceno (Caldasso 1967, Sial et al. 1981, Brito-Neves 1982). Alguns parecem constituir derrames.

A orientação N-S desses centros vulcânicos é difícil de explicar. Resultariam do deslocamento da placa para oeste, mas não há outros alinhamentos assim orientados no Nordeste. Sial (1976b) supõe a presença de um ponto quente móvel sob o bloco continental durante o Terciário, mas as datações disponíveis não o confirmam. O Alinhamento Macau-Queimadas e o de São Rafael, subparalelo, tal como definidos por Almeida et al. (1988), ainda aguardam uma explicação plausível.

A pequena província alcalina de Messejana, próximo a Fortaleza, tem sido estudada por diversos investigadores (apud Almeida et al. 1988), que reconheceram rochas de mesma natureza que as descritas no arquipélago de Fernando de Noronha. As de Messejana têm cerca de $30 \mathrm{Ma}$ (Cordani 1970; Thomaz-Filho 1983), enquanto as do arquipélago foram datadas em 2 a 12 Ma (Cordani 1970).

As rochas da Província de Messejana têm sido referidas como prova do prolongamento, à margem continental, de uma zona de fraturas oceânicas (Almeida 1958, Gorini \& Bryan 1976, Sykes 1978).

Bacia do Ceará Esta bacia está localizada na plataforma continental da margem equatorial brasileira, ocupando aproximadamente $34000 \mathrm{~km}^{2}$ entre os meridianos $38^{\circ}$ e $42^{\circ}$ W. Limita-se a sudeste pelo Alto de Fortaleza, da Bacia Potiguar, e a noroeste pelo Alto de Tutóia, da Bacia de Barreirinhas. A presença de características tectônicas distintas e feições estruturais proeminentes levou à sua subdivisão em quatro sub-bacias, de oeste para leste: Piauí-Camocim, Acaraú, Icaraí e Mundaú (Beltrami et al. 1994).

$\mathrm{Na}$ Bacia do Ceará aparentemente os episódios magmáticos foram restritos embora exista importante sucessão de vulcânicas em sua região oriental, a Sub-bacia de Mundaú. Nesta porção, sob a forma de corpos intrusivos de diabásio e extrusivos de basalto, caracteriza-se a Formação Macau, já definida por Mayer (1974) na Bacia Potiguar. As datações disponíveis conferem a essas rochas ígneas idade meso-eocênica a neooligocênica, ligeiramente mais nova em comparação ao vulcanismo Abrolhos, da Bacia do Espírito Santo.

Segundo Beltrami et al (1994), em águas profundas, caracteriza-se a presença de guyots, que ocorrem principalmente no sopé continental. Estas vulcânicas atravessam toda a seção sedimentar, desde o E-aptiano até o Recente. Seções sísmicas mostram apófises de basalto que se intercalam com os sedimentos, além de sequências sedimentares que recobrem as paredes laterais dos guyots em onlap, indicando que o vulcanismo processou-se por pulsos nesta porção de águas profundas.

As sub-bacias de Acaraú e Piauí-Camocim contêm pouco magmatismo basáltico, pelo que se noticia. Na primeira foram perfurados basaltos do Cretáceo médio, em local assinalado no Mapa Geológico do Brasil (Schobbenhaus et al. 1981). Na sub-bacia Piauí-Camocim, rochas ígneas básicas foram perfuradas pelo poço PIS-1, em seção albiana-inferior (Zalán \& Warme 1985).

No Alto do Ceará, que separa essas duas sub-bacias, foi perfurado o poço CES-87 (apud Zalán \& Warme 1985) que penetrou $800 \mathrm{~m}$ em uma seção de conglomerados e brechas intercaladas com rochas vulcânicas, sem contudo atingir a sua base. Testemunhos aí obtidos contêm fragmentos de granitoriólito em matriz arenosa arcosiana. É assim o Alto do Ceará um complexo intrusivo-vulcânico de lavas riolíticas surgido durante o estágio de cisalhamento da Bacia do Ceará. Mizusaki (inf. escrita, Almeida et al. 1988), utilizando o método K/Ar em feldspatos separados da brecha vulcânica do poço CES-87, determinou idade de cerca de 44 Ma para essa atividade ígnea. Tal manifestação magmática eocênica é encontrada também no Alto Atlântico (Szatmari et al. 1987).

Nada se conhece desse vulcanismo ácido no continente emerso vizinho. Ele parece estar limitado à Zona de Fratura Remanche, em sua extensão continental.

Bacias a oeste da Bacia do Ceará São desconhecidos registros magmáticos a oeste do Arco de Tutóia, limite ocidental da Bacia do Ceará, incluindo-se as bacias marginais de Barreirinhas, São Luís e Bragança-Viseu. A região continental adjacente tem somente magmatismo trapeano jurássico-eocretáceo da bacia epicontinental do Parnaíba.

Bacia da Foz do Amazonas A Bacia da Foz do Amazonas ocupa $268000 \mathrm{~km}^{2}$ no extremo oeste da margem equatorial brasileira. Nesta região foram perfurados 61 poços e há o registro de $63000 \mathrm{~km}$ de seções sísmicas de reflexão que permitiram delinear seu arcabouço estratigráfico (Brandão \& Feijó 1994).

No oriente do Amapá existe grande enxame de diques de diabásio e gabro de Cassiporé (Lima et al. 1974), orientados paralelamente à costa, em direção NNW, independentemente da direção das estruturas pré-cambrianas regionais. Alguns deles têm mais de $140 \mathrm{~km}$ de extensão (Oliveira \& Montes 1984). Foram datados por Teixeira (1978, apud Asmus 1984), tendo sido encontrados valores de 225,207 e $176 \mathrm{Ma}$. Na bacia marginal adjacente, no Graben do Cassiporé, a fase rifte, triássica, é atestada por atividade vulcânica datada de $206 \mathrm{Ma}$ (poço l-APS-25, PETROBRAS, apud Asmus 1984).

O rifteamento da costa norte, mais antigo, tem sido considerado como prolongamento sul-sudeste da abertura do Atlântico Norte (Smith \& Braiden 1977 apud Conceição et al 1988). Não se conhecem equivalentes, no continente emerso adjacente, dos basaltos neocretáceos $(90 \mathrm{Ma})$ reconhecidos por perfurações da PETROBRAS na margem continental submersa (apud Asmus 1984) na Bacia da Foz do Amazonas.

O magmatismo mais antigo, do Triássico ao Jurássico inferior, é evidentemente correlato dos diques da área emersa adjacente que, entretanto, parece não apresentar magmatismo neocretáceo.

Na Bacia da Foz do Amazonas reconhece-se a Formação Calçoene. Trata-se de um pacote vulcano-sedimentar, constituído por rochas ígneas básicas toleiíticas, intercaladas com arenitos (Brandão 1990). A idade neotriássica-eojurássica é deduzida com base em datações $\mathrm{K} / \mathrm{Ar}$ dos derrames associados, cujos resultados, analisados com indicações estratigráficas, mostram 186 a $222 \mathrm{Ma}$. 
Discussão e Considerações Finais Os eventos termo-tectônicos pós-paleozóicos possuem etapas relativamente bem marcadas na porção oriental da Plataforma Sul-Americana (Tab. 1). Variado e profuso magmatismo está associado a essas fases, constituindo-se em uma das mais seguras pistas dessa evolução, na margem continental já pesquisada - em que pesem o incompleto conhecimento do registro geológico e a limitada amostragem.

A natureza e a idade do magmatismo que se processou nas bacias da margem continental e altos tectônicos que as separam, ao longo da costa brasileira, quando analisadas em conjunto com o das áreas emersas vizinhas, apresentam clara e frequente correlação, reconhecível a dezenas ou mais de uma centena de quilômetros continente adentro. $\mathrm{O}$ magmatismo registrado entre o Mesozóico e o Cenozóico foi seguramente responsável pela formação de depósitos minerais na área continental, como os associados aos carbonatitos e as intrusões alcalinas espalhadas pelo sul-sudeste. São excelentes exemplos a fluorita na região de Santa Catarina e, possivelmente, também na região do Vale do Ribeira (R.B. da Silva 1992, inf. verbal). Ocorrem, ainda, bentonitas relacionadas à decomposição de rochas vulcânicas alcalinas da Formação Macau e do Vulcanismo Itapororoca (Carneiro \& Figueira 1994).

As manifestações mais remotas - entre o Triássico e o Jurássico inferior - restringiram-se à parte norte da plataforma, afetando mormente a área continental, no trecho compreendido entre as áreas cratônicas Amazônica e São Luís (Fig. 1). A margem oceânica adjacente é pouco conhecida, possibilitando recompor somente a natureza basáltica do magmatismo, de idade próxima a $200 \mathrm{Ma}$, que atingiu o Gráben de Cassiporé e a zona costeira adjacente, adentrando rumo sul, ao longo da Geossutura Tocantins-Araguaia (Almeida et al. 1986).

O vulcanismo basáltico da fase rifte, de idade neojurássica mas sobretudo eocretácea pré-aptiana, representa-se amplamente nas camadas inferiores das bacias da região sul-sudeste, Santos e Campos, e estende-se à Bacia do Espírito Santo, assim como aos altos que as separam, Florianópolis e Cabo Frio. Suas idades K/Ar mais frequentes estão entre 120 e 135 Ma. Essas rochas podem relacionar-se aos derrames de basalto toleiítico da Formação Serra Geral no continente e intrusões que se lhes associam. São atribuídas à presença do hotspot de Tristão da Cunha. Nas bacias marginais e altos desconhecemse equivalentes _ no estágio atual dos conhecimentos _ das lavas ácidas dessa formação, que ocorrem no sul da Bacia do Paraná e no planalto de Etendeka (na Namíbia), sudoeste da
África (Piccirillo et al. 1988), correlates da referida bacia. Do mesmo modo, não são ainda conhecidas, na região de Pelotas, rochas similares às intrusões alcalinas feldspatoidais pré-aptianas que se associam a esse vulcanismo.

O magmatismo eocretáceo arrefeceu no Aptiano-Albiano, ao que parece, tanto no continente quanto nas bacias marginais dessa região do país, mas voltou a crescer em intensidade durante o Neocretáceo e o Eoceno. No continente, tem caráter alcalino, subsaturado, predominantemente félsico. Nas bacias marginais parece ser sobretudo subalcalino/alcalino. Rochas alcalinas feldspatoidais também devem ocorrer, na provável extensão do Alinhamento de Cabo Frio em direção ao mar. Elas seguramente afloram em ilhas na região costeira paulista. São tidas como projeção, continente adentro, dos lineamentos oceânicos de Porto Alegre e Rio de Janeiro, embora para nem todas essa correlação seja tão clara, como no Alinhamento de Cabo Frio, longo colar de corpos intrusivos e manchas de efusivas alcalinas. Efusivas eocênicas ocorrem nesse alinhamento magmático emerso, bem como na plataforma continental de Cabo Frio e na parte sul da Bacia de Campos, onde são particularmente importantes.

Deve-se observar que o magmatismo terciário nas bacias marginais e no continente emerso vizinho, no sul-sudeste do Brasil, cessou aparentemente após o Eoceno. Aliás, parece ser esse o caso também das regiões remotas do interior do Brasil Central e Meridional, onde a presença do próprio magmatismo eocênico é duvidosa. Assim, idades de 45 Ma de um álcaliolivina basalto da Serra de Bueno (GO) e de 43 Ma de um ugandito (?) de Sacramento (MG) são citadas com interrogação por Ulbrich \& Gomes (1981). A idade de 53 Ma obtida para o fonólito de Poços de Caldas foi posta em dúvida por Ulbrich (1984), enquanto a idade de 54 Ma para uma lava de analcita fonólito de Jaboticabal (SP), obtida por Gomes \& Valarelli (1970), também foi tida como duvidosa por Coimbra et al. (1981), pois se intercala no Grupo Bauru, de idade cretácea. São todas datações pelo método $\mathrm{K} / \mathrm{Ar}$ indicando provavelmente idades mínimas, por perda de Ar. Não parece ser o caso de idades obtidas na região de Assunção (Paraguai), onde as rochas eocênicas têm sido comprovadas (Comte \& Hasui 1971,Stormer et al. 1975 e Palmieri\& Velasquez 1982, Gomes et al. 1996).

Magmatismo cretáceo inferior parece estar ausente, tanto nas bacias marginais quanto no continente emerso vizinho, para norte do Banco de Abrolhos, constituído de rochas magmáticas neocretáceas e eoterciárias ou possivelmente do Banco Royal Charlotte, mais a norte, na costa sul da Bahia, cuja natureza vulcânica é admitida. Tal magmatismo do

Tabela 1 - Incidência de magmatismo pós-paleozóico nas bacias marginais, nos altos que as separam, e na área continental adjacente, no Brasil.

Table I-Post-Paleozoic magmatic activity in marginal basins, in the dividing structural highs and in the adjoining continental areas, in Brasil.

\begin{tabular}{|c|c|c|c|c|c|}
\hline \multirow{2}{*}{$\begin{array}{l}\text { Bacia ou Alto Estrutural } \\
\text { oceânicos e área continental vizinha }\end{array}$} & \multicolumn{5}{|c|}{ MAGMATISMO } \\
\hline & $\begin{array}{c}\text { Triássico- } \\
\text { Jurássico inf. }\end{array}$ & $\begin{array}{c}\text { Jur. sup. a } \\
\text { Eocretáceo pré- } \\
\text { aptiano }\end{array}$ & Aptiano-Albiano & $\begin{array}{c}\text { Neocretáceo a } \\
\text { Eoceno }\end{array}$ & $\begin{array}{c}\text { Oligoceno a } \\
\text { Mioceno }\end{array}$ \\
\hline Bacia de Santos & - & $*$ & - & * & - \\
\hline Alto Estrutural de Florianopolis & - & * & - & - & - \\
\hline Bacia de Pelotas & - & * & - & - & - \\
\hline Alto de Cabo Frio & - & * & - & * & - \\
\hline Bacia de Campos & - & * & - & * & - \\
\hline Bacia do Espírito Santo & - & * & - & * & - \\
\hline Platô de Pernambuco & - & $* ?$ & * & - & - \\
\hline Bacia Potiguar & - & $*$ & - & - & * \\
\hline Bacia do Ceará & - & $?$ & $*$ & $*$ & * \\
\hline Bacias a Oeste da Bacia do Ceará & - & $*$ & - & - & - \\
\hline Bacia da Foz do Amazonas & * & - & - & * & _ \\
\hline Bacia do Amapá & * & _ & - & * & _- \\
\hline
\end{tabular}


Cretáceo inferior vai ressurgir no Platô de Pernambuco e, na costa, na região do Cabo de Santo Agostinho, a sul de Recife.

A extensão do Cráton de São Francisco à costa é tida como um dos motivos da ausência de magmatismo em uma parte da costa baiano-sergipana (Asmus 1982). Seria uma explicação adequada para o trecho entre a foz do rio Jequitinhonha e o sistema de falhas pré-cambrianas de Itaporanga d'Ajuda que separa o cráton da Bacia Sergipe-Alagoas. A hipótese de que tal bacia tenha caráter de rifte passivo (Carneiro et al. 1989) pode explicar em parte essa ausência de vulcanismo, tanto na bacia como na área emersa adjacente. Ademais, a bacia que se dispõe obliquamente às estruturas do Sistema Marginal Sergipano é semelhante ao caso da Bacia de PernambucoParaíba. O tipo de rifte físsural para norte da Bacia de Campos e não tipo arco vulcânico, característico para a região sulsudeste (Asmus \& Guazelli 1981) explicaria a escassez ou ausência de magmatismo nessas bacias da margem continental leste e continente emerso vizinho. Fenômeno similar afetou o sistema de bacias Recôncavo-Tucano-Jatobá. Há, contudo, que lembrar a presença do hotspot de Tristão da Cunha, condicionando o magmatismo da Formação Serra Geral e do sudoeste da África.

Esses fatos reforçam a ideia de que ao vulcanismo do Platô de Pernambuco e da região costeira se associa o mais recente granito emerso brasileiro, o Granito do Cabo.

O sistema de diques da Formação Rio Ceará-Mirim, no Rio Grande do Norte, segundo o modelo de Françolim \& Szatmari (1987) resultou de esforços de distensão consequentes da rotação horária da placa ao redor do pólo de rotação que esses autores situam no Cretáceo inferior, a sul de Fortaleza e norte da Bacia de Tucano. As idades próximas de $135 \mathrm{Ma}$ obtidas para esses diques, comparadas com as de derrames basálticos penetrados por perfurações da PETROBRAS no Alto de Touros, na parte submersa da Bacia Potiguar (130 Ma) e outro datado pela posição estratigráfica (apud Asmus \& Guazelli 1981), parecem indicar que resultam do mesmo pulso magmático da fase rifte da bacia, à semelhança do que se observa na região sul-sudeste.

No Nordeste oriental, o magmatismo terciário prosseguiu no Oligoceno, na sub-bacia Mundaú e no Vulcanismo Messejana, no Ceará, e mesmo até o Mioceno, na Bacia Potiguar emersa e submersa no Rio Grande do Norte, estendendo-se à região de embasamento cristalino a sul (Formação Macau), na Paraíba.

Uma das causas possíveis da aparente escassez de magmatismo nas bacias marginais situadas desde a região ocidental da Bacia do Ceará até Bragança-Vizeu (ver Fig. 3) e margem continental emersa adjacente é que este trecho da borda continental seccionou o Cráton de São Luís, não afetado pela orogênese brasiliana, enquanto as sub-bacias de Acaraú e Mundaú, na Bacia do Ceará, acham-se em região ativada pelo evento Brasiliano, que afetou estruturas pré-cambrianas mais antigas, oblíquas à costa.

O Alto Atlântico e o Alto do Ceará, na sub-bacia PiaúCamocim, representam extensão, ao continente, da Zona de Fratura oceânica Remanche (Zalán \& Warme 1985) que assim secciona, em sua terminação, o Cráton de São Luis. A natureza ácida do vulcanismo-plutonismo desses altos assemelha-se, como observaram Zalán \& Warme (1985), à Formação Ipojuca e ao Granito do Cabo de Santo Agostinho, igualmente na extensão continental do Lineamento oceânico de Pernambuco.

A atenuação, ou mesmo ausência, de magmatismo aptianoalbiano é notada nas bacias do Espírito Santo para sul e região costeira adjacente, com possível exceção (alteração?) de datação de 113 Ma na Bacia de Pelotas, porém ele se manifestou na região Nordeste, na Bacia do Ceará e na plataforma continental do Amapá, na Bacia da Foz do Amazonas.

Enquanto na região sul-sudeste a atividade magmática aparentemente cessou no Oligoceno, no Nordeste oriental ela prosseguiu até o Mioceno.

Pode-se sugerir que o magmatismo terminou mais cedo na região sul-sudeste e bacias próximas, da margem continental, que na região Nordeste e bacias do Ceará e Potiguar, como consequência do afastamento mais cedo da América do Sul e da África, resultante da rotação em sentido horário daquele continente, ao redor do pólo. Entretanto, as ainda pouco conhecidas condições térmicas do manto, a natureza e estrutura da crosta e as consequentes condições dos processos de rifteamento devem ter sido fatores igualmente determinantes na distribuição espacial e temporal do magmatismo nas bacias marginais e áreas continentais adjacentes.

Agradecimentos A realização do presente estudo recebeu apoio do Instituto de Pesquisas Tecnológicas do Estado de São Paulo (IPT), a quem os autores agradecem, bem como à PETROBRAS-DEPEX que possibilitou, por intermédio dos geólogos Dr. Giuseppe Bacoccoli e Dr. Laércio Gonzaga de França Aranha, acesso a mapas e relatórios inéditos, produzidos até 1988, alguns dos quais não citados no texto. As ilustrações foram elaboradas pela Sra. Damaris R. Marins, a quem os autores são gratos. Os autores agradecem ainda as oportunas e enriquecedoras sugestões formuladas por dois anônimos revisores da RBG.

\section{REFERÊNCIAS}

ALMEIDA, F.F.M. de. 1955. Geologia e Petrologia da Ilha de Trindade. Rio de Janeiro: DNPM/DGM. 197 p. (Monogr. 18)

ALMEIDA, F.F.M. de. 1958. Geologia e petrologia do Arguipélago de Fernando de Noronha. Rio de Janeiro: DGM/DNPM. 158 p. (Monogr. 13).

ALMEIDA, F.F.M. de. 1960. Quelques aspects sous-marins au large de Ia cote brésilienne. In: INTERN. GEOL. CONG., 21, Norder, 1960. Report... Copenhagen, part 10. Submarine Geology, p.23-28.

ALMEIDA, F.F.M. de. 1961. Geologia e petrologia da Ilha de Trindade. Rio de Janeiro: Div. Geol. Miner. DNPM., 198 p., mapa. (Monogr .XVIII)

ALMEIDA, F.F.M. de. 1986. Distribuição regional e relações tectônicas do magmatismo pós-paleozóico no Brasil. Rev. Bras. Geoc., v. 16, n. 4, p. 325-349.

ALMEIDA, F.F.M. de. 1991.0 alinhamento magmático de Cabo Frio. SIMP. GEOL. SUDESTE, 2, São Paulo, 1991. Atas... São Paulo: SBG/ NSP-RJ.p. 423.428.

ALMEIDA, RF.M.de; CARNEIRO, C.D.R.; DEHIRA, L.K.; MACHADO JÚNIOR, D.L. 1988. Magmatismo pós-paleozóico no Nordeste Oriental Brasileiro. Rev. Bras. Geoc., v. 18, n. 4, p. 451-462.
ALMEIDA, F.F.M. de; FERREIRA, F.J.F.; CARNEIRO, C.D.R. \& STEFANI, F.L. 1986. Aspectos evolutivos da Geossutura Tocantins-Araguaia. In: CONGR. BRAS. GEOL., 34, Goiânia, 1986. Anais... Goiânia, SBG. v. 3, p. 1269-1284.

ALVES, E.C. 1981. Estruturas da margem continental sul brasileira e das áreas oceânicas e continentais, adjacentes. In: PETROBRAS. Estruturas e tectonismo da margem continental brasileira, e suas implicações nos processos sedimentares e na avaliação do potencial de recursos minerais; relatório final. Rio de Janeiro, CENPES/DINTEP. p. 145-170. (Projeto REMAC 9).

ALVES, E.C. \& COSTA, M.P.A. 1981. Estrutura da margem continental sul brasileira das áreas oceânicas continentais e adjacentes. Rio de Janeiro: PETROBRÁS/CENPES/DINTEP, 1981, p. 145-169. (Série Projeto REMAC, 4)

ALVES, E.C. \& COSTA, M.P.A. 1986. Interpretação sismo-estratigráfica da porção norte do Platô de Pernambuco e suas possíveis correlações com a Bacia de Pernambuco-Paraíba. In: CONGR. BRAS. GEOL., 34, Goiânia, 1986. Anais... Goiânia: SBG. v. 1, p. 286-297. 
AMARAL, A.J.R. \& MENOR, E.A. 1979. A sequência vulcano-sedimentar cretácea na região de Suape (PE): Interpretação faciológica e consideracões metalogenéticas. In: SIMP. GEOL. NORDESTE, 9 , Natal, 1979. Atas... Natal: SBG/NNE. p. 251-269. (Bol. 7).

AMARAL, G.; CORDANI, V.G.; KAWASHITA, K.; REYNOLDS, J.H. 1967. Potassium-argon ages of alkaline rocks from southern Brasil. Geoch. Cosmoch. Acta, n. 31. p. 117-142.

AMERICAN ASSOCIATION OF PETROLEUM GEOLOGISTS. AAPG. 1983. Geologic Time Scale. Boulder, Colorado: AAPG.

ARARIPE, P.T. \& FEIJÓ, F.J. 1994. Bacia Potiguar. Bol. Geoc. Petrobras, v. 8, n. 1, p. $127-142$.

ASMUS, H.E. 1982. Geotectonic significance of Mesozoic-Cenozoic magmatic rocks in the Brazilian continental margin and adjoining emerged area. In: CONGR. LATINO-AMERICANO GEOL., 5, Buenos Aires, 1982. Actas... Buenos Aires: Servido Geológico Nacional, v.3, p.761-779.

ASMUS, H.E. 1984. Geologia da margem continental brasileira. In: SCHOBBENHAUS, C.; CAMPOS, D.A.; DERZE, G.R.; ASMUS, H.E. coords. Geologia do Brasil. Texto explicativo do mapa geológico do Brasil e da área oceânica adjacente incluindo depósitos minerais Brasilia: DNPM. p.443-472

ASMUS, H.E. \& BAISCH, P.R. 1983. Geológical evolution of Brazilian continental margin. Episodes, n. 4, p. 3-9.

ASMUS, H.E. \& GUAZELLI, M. 1981. Descrição sumária das estruturas da margem continental brasileira e das áreas oceânicas e continentais adjacentes, hipóteses sobre o tectonismo causador e implicações para os prognósticos de recursos minerais. In: PETROBRAS. Estruturas e tectonismo da margem continental brasileira, e suas implicações nos processos sedimentares e na avaliação do potencial de recursos minerais; relatório final. Rio de Janeiro, CENPES/DINTEP. p. 187-269. (Projeto r REMAC, Boi. Geoc. Petrobras, v. 8, n. 1, p. 117-126.

BINKS, R.M. \& FAIRHEAD, J.D. 1992. A plate tectonic setting for Mesozoic rifts of West and Central África. Tectonophysics, v. 213, n. $1 / 2$, p. $141-151$.

BRANDÃO, J.A.S.L. 1990. Revisão e atualização esíratigráfica das bacias da Foz do Amazonas e Pará Maranhão. Rio de Janeiro: Petrobras. (Rel. int.).

BRANDÃ̃O, J.A.S.L. \& FEIJÓ, F.J. 1994. Bacia da Foz do Amazonas. Bol. Geoc. Petrobras, v. 8, n. 1, p. 91-100.

BRITO-NEVES, B.B. de 1982. Síntese da geocronologia. In: Mapa Geológico do Estado da Paraíba, texto explicativo. Campina Grande: SERM/CDRM. p. 55-69.

CAINELLI, C. 1992. Sequence stratigraphy, canyons andgravity mass-flow deposits in the Piaçabuçu Formation, Sergipe-Alagoas Basin, Brasil. Austin: University of Texas at Austin. 233 p. (PhD dissertation).

CALDASSO, A.L. 1967. Geologia da quadrícula E-093, Folha Crato. Recife: SUDENE/Div. Geologia. 39p.

CARNEIRO, C.D.R. \& FIGUEIRA, R.M. 1993. Depósitos minerais associados à Ativação Mesozóica no Nordeste Oriental Brasileiro. Revista de Geologia, UFCe. v. 6, p. 5-31

CARNEIRO, C.D.R.; HAMZA, V.M.; ALMEIDA, F.F.M. de. 1989. Ativação tectônica, fluxo geotérmico e sismicidade no Nordeste Oriental brasileiro. Rev. Bras. Geoc., v. 19, n. 3, p. 310-322.

CARNEIRO, C.D.R.; MONMA, R.; FERREIRA, F.J.F.; DEHIRA, L.K 1988. Ensaio de integração geológico-geofisica do Nordeste Oriental com base em mapas aeromagnéticos. In: CONGR. BRÁS. GEOL., 35, Belém, 1988. Anais... Belém, SBG. v. 5, p. 2122-2136.

CARRARO, C.C.; ISSLER, R. S.; FORMOSO, M.L.L. 1967. Mapeamento do distrito alcalino de Altos do Rio Pinheiros, Municipio de Anitápolis. Estado de Santa Catarina. Porto Alegre: Univ. Fed. Rio Grande do Sul, 45p. (Publ. Espec. n. 16).

CARVALHO, J.C.de \& FRANCISCONI, O. 1981. Análise de depocentros, e suas associações com a geomorfologia e a estrutura da margem continental brasileira. In: PETROBRAS. Estruturas e tectonismo da margem continental brasileira, e suas implicações nos processos sedimentares e na avaliação do potencial de recursos minerais, relatório final. Rio de Janeiro, CENPES/DINTEP. p.171-1 86. (Projeto REMAC, 9).

CHANG, H.K.; KOWSMAN, R.O.; FIGUEIREDO, A.M.F.; BENDER, A. A. 1992. Tectonics and stratigraphy of the East Brazil Rift System. Tectonophysics, v. 213, n. 1/2, p. 97-138.

COIMBRA, A.M. COUTINHO, J.M.V.; BRANDT NETO, M.; ROCHA, G.A.1981. Lavas fonolíticas associadas à Formação Bauru em São Paulo. In: SIMP. REG. GEOL., 3,1981. Atas... Curitiba: SBG/NSP. v. 1, p. 324-327.

COMTE, D. \& HASUI, Y. 1971. Geochronology of Eastern Paraguay by potassium-argon method. Rev. Bras. Geoc., v. 1, n. 1, p. 33-43.
CONCEIÇÃO, J.C.J.; MIZUSAKI, A.M.P.; ALVES, D.B. \& SZATMARI, P. 1994. Controle tectônico do magmatismo meso-cenozóico no sul e sudeste do Brasil e seu papel na evolução das bacias sedimentares. Rio de Janeiro: Petrobras. (Rel. int.).

CONCEIÇÃO, J.R.de; ZÁLAN, P.V.; WOLFF, S. 1988. Mecanismo, evolução e cronologia do rift sul atlântico. B. Geoc. Petrobras, v. 2, n. $2 / 4$, p. $255-265$

CORDANI, U.G. 1970. Idade do vulcanismo do Oceano Atlântico Sul. São Paulo: Bol IGA, v. 1, p. 9-75.

CORDANI, V.G.; HALPERN, M. BERENHOLC, M. 1974. Comentários sobre a determinações geocronológicas da Folha de Porto Alegre. In SCHOBBENHAUS FILHO, et al. Carta Geológica do Brasil ao Milionésimo; folhas Porto Alegre SH.22 e Lagoa Mirim, SI.22. Brasília: DNPM/MME, 99p.

DAMASCENO, E.C. 1966. Estudo preliminar dos diques de rochas básicas e ultrabásicas da região de Ubatuba, Estado de São Paulo. An. Acad. bras. Ciênc., v. 38, n. 2, p. 293-304.

D'ELBOUX, C.V.; TAVARES, J.R.P.; PAIVA, I.B. 1982. Proposição de modelo mineralizador básico alcalino para pesquisa mineral na região meridional do escudo pré-cambriano brasileiro. In: CONGR. BRAS. GEOL., 32, Salvador, 1982. Anais... Salvador: SBG. v. 3,p.1061.1072.

DIAS, J.L; SAD, A.R.E.; FONTANA, R.L. \& FEIJÓ, F.J. 1994. Bacia de Pelotas. Bol. Geoc. Petrobras, v. 8, n. 1, p. 235-245.

FAIRHEAD, J.D. 1988. Mesozoic plate tectonic reconstructions of the central South Atlantic Ocean: the role of the West and Central African rift system. Tectonophysics, v. 155, n. 1-4, p. 181-191.

FEIJÓ, F.J. 1994. Bacia de Sergipe-Alagoas. Bol. Geoc. Petrobras, v. 8, n. 1, p. $149-162$.

FIGUEIREDO, A.M.F. \& GABAGLIA, G.P.R. 1986. Sistema classificatório aplicado às bacias sedimentares brasileiras. Rev. Bras. Geoc., v. 16, n. 4, p. 350-369.

FRANÇOLIM, J.B.L. \& SZATMARI, P. 1987. Mecanismo de rifteamento da porção oriental da margem norte brasileira. Rev. Bras. Geoc., v. 17, n. 2, p. 195-207.

GABAGLIA, G.P.R. \& FIGUEIREDO, A.M.F. 1990. Evolução dos conceitos acerca das classificações de bacias sedimentares. In: GABAGLIA, G.P.R. \& MILANI, E.J. coords. Origem e evolução de bacias sedimentares. Rio de Janeiro: Petrobras. p. 31-45.

GASS, I.G. 1973. The Red Sea Depression: causes and consequences. In: TARLING, D.H. \& RUNCORN S.K., eds. Implications of continental drift for the earth sciences. Academy Press, 1973. v. 2, p. 779-86.

GAVA, A.; NASCIMENTO, D.A.do; VIDAL, J.L.B.; GHIGNONE, J.I.; OLIVEIRA, E.P.de; SANTIAGO FILHO, A.L.; TEIXEIRA, W.; STANFORD, W..J.P.; RIBEIRO, A.G.; RIBEIRO, J.H.M. 1983. Geologia. In: PROJETO RADAMBRASIL. Folha SC.24/25 Aracaju/Recife; geologia, geomorfologia, pedologia, vegetação e uso potencial da terra. Rio de Janeiro, MME/Secretaria Geral. p. 27-376 (Lev. Rec. Nat. 30).

GOMES, C.B. \& VALARELLI, J.V. 1970. Novas ocorrências de rochas alcalinas no Estado de São Paulo. In: CONGR. BRAS. GEOL. 24, Brasília, 1970. Bol. Esp.... Brasília: SBG., p. 336 (n. 1)

GOMES, C.B.; COMIN-CHIARAMONTI, P.; VELÁZQUEZ, V.F. \& ORUÉ, D. 1996. Alkaline magmatism in Paraguay: a review. In: COMIN-CHIARAMONTI, P. \& GOMES, C.B. eds. Alkaline magmatism in Central-Eastern Paraguay. São Paulo: Ed. Univ. São Paulo. p. 31-56.

GOMES, J.R.C.; GATTO, C.M.P.P.; SOUZA, G.M.C.de; LUZ, D.S.da; PIRES, J.L.; TEIXEIRA, W.; FRANCA, F.A.B.de; CABRAL, E.M.A.; MENOR, E.A.; MONTEIRO, N.; BARROS, M.J.G.; RIBEIRO, E.G.; LIMA, E.A.de; FONSECA, R.A.da. 1981. Geologia. In: PROJETO RADAMBRASIL. Folhas SB.24/25 Jaguaribe e Natal; geologia, geomorfologia, pedologia, vegetação e uso potencial da terra. Rio de Janeiro, MME/Secretaria Geral. p. 27-300 (Lev. Rec. Nat. 23).

GORINI, M.A. 1981. The tectonic fabric of the equatorial Atlantic and adjoining continental margins. In: PETROBRAS. Estruturas $e$ tectonismo da margem continental brasileira, e suas implicações nos processos sedimentares e na avaliação do potencial de recursos minerais; relatório final. Rio de Janeiro, CENPES/DINTEP. p. 11-116. (Projeto REMAC 9).

GORINI, M. A. \& BRYAN, G.M. 1976. The tectonic fabric of the Equatorial Atlantic and adjoining continental margins: Gulf of Guinea to Northeastern Brazil. An. Acad. bras. Ciênc., v. 48 (supl.), p. 101-119. GUAZELLI, W. \& CARVALHO, J.C. 1981. Estrutura da margem continental leste brasileira e das áreas continentais e oceânicas adjacentes. In: PROJETO REMAC. Aspectos estruturais da margem continental leste e sudeste do Brasil. Rio de Janeiro: PETROBRÁS/CENPES/ DINTEP. (Série Projeto REMAC 9).

GUIRAUD, R. \& MAURIN, J-C. 1992. Early Cretaceous rifts of Western and Central África: an overview. Tectonophysics, v. 213, n. 1/2, p. 153-168. 
HENNIES, W.T. \& HASUI, Y. 1968. Geocronologia das rochas eruptivas alcalinas da Ilha de São Sebastião, SP. In: CONGR. BRAS. GEOL., 22, Belo Horizonte, 1968. Anais... Belo Horizonte: SBG. p. 145-148.

HOFFMAN, P.F. 1991. Did the breakout of Laurentia turn Gondwanaland inside-out? Science, v. 252, p. 1409-1412.

KINGSTON, D.R.; DISHROON, C.P.; WILLIAMS, P.A. 1983a. Global basin classification system. Am. Assoe. Petr. Geol. Bull, v. 67, n. 12 p. $2175-2193$

KINGSTON, D.R.; DISHROON, C.P.; WILLIAMS, P.A. 1983 b. Hydrocarbon plays and global basin classification. Am. Assoc. Petr. Geol. Bull, v. 67, n. 12, p. 2194-2198.

KLEIN, V.C. \& VALENCA, J.G. 1984. Estruturas almofadadas em derrame ankaramítico na Bacia de São José de Itaboraí, Rio de Janeiro. In: CONGR. BRÁS. GEOL., 33, Rio de Janeiro, 1984. Anais... Rio de Janeiro: SBG. v. 9, p. 4335-4345.

LIMA, M.I.C.; MONTALVÃO, R.M.G.D.; ISSLER, R.S.; OLIVEIRA, A.S.; BASEI, M.A.S.; ARAUUJO, J.F.V.; SILVA, G.G. da. 1974 Geologia. In: BRASIL/MME-SG. Projeto RADAM. Folha NA/NB 22. Macapá. Rio de Janeiro. (Levantamento de Recursos Naturais, 6).

MACIEL FILHO, C.L. \& SARTORI, P.L.P. 1979. Aspectos estruturais da região de São Francisco de Assis, RS. Ci Nat., Santa Maria, n. 1, p. 53-65.

MAGNAVITA, L.P. 1990. Geometry and kinematics of the Recôncavo-Tucano-Jatobá R:ft. In: SIMP. SOBRE A BACIA DO ARARIPE E BACIAS INTERIORES DO NORDESTE., 1, 1990. Anais... Crato: SBG. v. 1, p. 67-81.

MARSH, I.S. 1973. Relationships between transform directions and alkaline igneous rock lineaments in Africa and South America. Earth Planei. Sci. Lett.. V. 18, p. 317-323.

MARTINS, G.; BELLIENI, G.; COMIN-CHIARAMONTI, P.; MELFI, A.J.; MACEDO, M.H.F.; PICCIRILLO, E.M. 1989. O enxame de diques máficos mesozóicos "Rio Ceará-Mirim" -Nordeste do Brasil. In: WORKSHOP "DIQUES MÁFICOS PRÉ-CAMBRIANOS DO BRASIL, 1, São Paulo, 1989. Anais... São Paulo: Projeto PICG - 257, IUGS-UNESCO.

MAYER, E. 1974. Estratigrafia preliminar na plataforma continental na Bacia Potiguar, Rio Grande do Norte s.1. PETROBRÁS (inédito).

MELFI, A.; PICCIRILLO, E.M.; NARDY, A.J. 1988. Geologic and magmatic aspects of the Paraná Basin an introduction. In: PICCIRILLO, E.M., MELFI, A.J. coords. The mesozoic flood basalts Of the Paraná Basin. São Paulo. Inst. Astron. Geol. Univ. São Paulo. p. $1-14$

MELANOVSKY, E.E. 1972. Continental rift zones: their arrangement and development. Tectonophysics, v. 5, n. 1-2, p. 65-70.

MIZUSAKI, A.M.P. 1986. Rochas igneo-básicas do Neocomiano da Bacia de Campos. Caracterização e comportamento como reservatório de hidrocarbonetos. Rio de Janeiro: Inst. Geof. UFRJ. 104p. (Dissertação de Mestrado, inédita)

MIZUSAKI, A.M.P. 1989. A Formação Macau na porção submersa da Bacia Potiguar. Bol Geoc. PETROBRÁS. v. 3, n. 3, p. 191-200.

MIZUSAKI, A.M.; ALVES, D.B.; CONCEICÃO, J.C.J. 1994. Eventos magmáticos nas bacias do Espirito Santo, Mucuri e Cumuruxatiba. CONGR. BRAS. GEOL. 38, Baln. Camboriú, 1994. B. Res. Expandidos... Baln. Camboriú: SBG. v. 1, p. 566-567.

MIZUSAKI, A.M.P. \& MOHRIAK, W.U. 1993. Sequências vulcânico-sedimentares na região da plataforma continental de Cabo Frio. (RJ). SIMP. GEOL. SUDESTE 3, Rio de Janeiro. 1993. Atas... Rio de Janeiro: SBG/NRJ-SP, p. 52-56.

MIZUSAKI, A.M.P.; PETRINI, R.; BELLIENI, G.; COMIN-CHIARAMONTI, P.; DIAS, S.J.; DE MIN, A.; PICCIRILLO, E.M. 1992. Basalt magmatism along the passive continental margin of SE Brazil (Campos Basin). Contrib. Mineral Petrol., v. 111, p. 143-160.

MIZUSAKI, A.M.P.; THOMAZ FILHO, A.; VALENCA, J. 1988. Volcano-sedimentar sequence of Neocomiam age in Campos Basin (Brazil) Rev. Bras. Geoc., v. 18. n. 3, p. 247-251.

OJEDA, H.A.O. \& ARANHA, L.G.F. 1980. Bacia de Santos, integração geológica regional. Rio de Janeiro: Petrobras. (Rel. int.).

OJEDA, H.A.O \& CESERO, P. 1973. Bacias de Santos e Pelotas, geologia e perspectivas petroliferas. Rio de Janeiro: Petrobras. (Rel. int.).

OLIVEIRA, E.P. \& MONTES, M.L. 1984. Os enxames de diques máficos do Brasil. In: CONGR. BRÁS. GEOL., 33, Rio de Janeiro, 1984. Anais... Rio de Janeiro: SBG. v. 9, p. 4137-4154.

PALMIERI, J.H. \& VELASQUEZ, J.C. 1982. Geologia dei Paraguay. Col. Apoyo a Cátedra. Asunción: Ediciones Napa. 65p.

PEREIRA, M.J.; BARBOSA, C.M.; AGRE, J.; GOMES, J.B; ARANHA, L. G. F.; SAITO, M.; RAMOS, M.A.; CARVALHO, M.D. de; STAMATO, M.; BAGNI, O. 1986. Estratigrafia da Bacia de Santos: análise das sequências, sistemas deposicionais e revisão litoestratigráfica. In: CONGR. BRÁS. GEOL., 34, Goiânia, 1986. Anais... Goiânia: SBG. v. 1, p. 65-79.

PEREIRA, MJ. \& FEIJÓ, F.J. 1994. Bacia de Santos. Bol. Geoc. Petrobras, v. 8, n. 1, p. $219-234$
PICCIRILLO, E.M.; BELLIENI, G.; COMIN-CHIARAMONTI, P.; ERNESTO, M.; MELFI, A.; PACCA, I.G.; USSAMI, N. 1988. Significance ofthe Paraná flood volcanism in the disruption of Western Gondwanaland. In: PICCIRILLO, E.M., MELFI, A.J. coords. The mesozoic flood basalts ofthe Paraná Basin. São Paulo. Inst. Astron. Geol. Univ. São Paulo. p. 285-295

PICCIRILLO, E.M.; MELFI, A.J. coords. 1988. The mesozoic flood vulcanism of the Paraná Basin. São Paulo: Inst. Astron. Geof. Univ. São Paulo. 599 p.

PINTO, J.F; VILLWOCK, J.A.; LOESS, E.L. 1975. Relatório de geologia da província alcalina do Rio Grande do Sul, folhas Arroio Barracões e Arroio da Bica. Porto Alegre: Inst. Geoc. UFRS/DNPM/MEC, 48 p. (inédito).

PONTE, F.C. \& ASMUS, H.E. 1976. The Brazilian marginal basins: current state of knowledge. An. Acad. bras. Ciênc., v. 48, (Supl.), p. 215-239 (Proc. International Symposium on continental margins of Atlantic type, São Paulo, 1975).

RANGEL, H.D. \& BORGES, A.Z. N. de. 1993. Estratigrafia e evolução estrutural da área sul (adjacente ao Alto Cabo Frio) da Bacia Campos In: SIMP. GEOL. SUDESTE, 3, Rio de Janeiro, 1993. Atas... Rio de janeiro: SBG/NRJ-SP, p. 57-63.

RANGEL, H.D.; MARTINS, F.A.L.; ESTEVES, F.R. \& FEIJÓ, F.J. 1994. Bacia de Campos. Bol. Geoc. Petrobras, v. 8, n. 1, p. $203-217$.

RENNE, P.R.; ERNESTO, M.; PACCA, I.G.; COE, R.S.; GLEN, J.M.; PRÉVOT, M.; PERRIN, M. 1992. The age of Paraná flood volcanism rifting of Gondwanaland and the Jurassic-Cretaceous boundary. Science, v. 258 , p. $957-959$.

RICCOMINI, C. 1989. O rift continental do sudeste do Brasil. São Paulo: Inst. Geoc. Univ. S. Paulo. (Tese de Doutoramento).

RICCOMINI, C.; APPI, C.J.; FREITAS, E.L. de; ARAI, M. 1987. Tectônica e sedimentação no sistema de riftes continentais da Serra do Mar (Bacias de Volta Redonda, Resende, Taubaté e São Paulo). In: SIMP. deGEOL.RJ-ES, 1, Rio de Janeiro, 1987.Anais... Rio de Janeiro: SBG. p. 253-298. (Roteiros das Excursões)

SADOWSKI, G.R. \& DIAS NETO, C. de M. 1981. O lineamento sismo-tectônico de Cabo Frio. Rev. Bras. Geol. v. 11, n. 4, p. 209-212.

SANFORD, R.M. \& LANGE, F.W. 1960. Basin study aproach to oil evolution ofthe Paraná mesogeosyncline, South Brazil. AAPG. Bull, v. 44 , n. 8, p. 1316-1370.

SANTOS, S.F. \& CASTRO, F.C.C. 1992. Mapa sísmico em águas profundas das bacias de Sergipe e Alagoas. Rio de Janeiro: Petrobras. (Rel int)

SCHEIBE, L.F. 1978, Okimberlito "Janjão", Lajes, Santa Catarina, Brasil; nota preliminar. Florianópolis.UFSC. (Painel de Pesquisas daUFSCl)

SCHEIBE, L.F.; KAWASHITA, K.; GOMES, C. de B. 1985. Contribuição à geocronologia do complexo alcalino de Lajes, SC. In: SIMP. SUL-BRAS. GEOL., 2, Florianópolis, 1985. Anais... Florianópolis: SBG/NRS-CS-PR. p. 299-308.

SCHOBBENHAUS, C.; CAMPOS, D.A.; DERZE, G.R.; ASMUS, H.E. coords. 1981. Mapa Geológico do Brasil e da área oceânica adjacente, incluindo depósitos minerais; escala 1:2.500.000. Brasília: DNPM/MME (4 folhas).

SIAL, A.N. 1976a. The post-paleozoic volcanism of northeast Brazil and its tectonic significance. An. Acad. bras. Ciênc., v. 48 (Supl.),p. 299-311.

SIAL, A.N. 1976b. The Rio Grande do Norte alcali-olivine-basalt association, Northeast Brazil. Rev. Bras. Geoc., v. 6, n. 1, p 1-14.

SIAL, A.N.; OLIVEIRA, E.P.; CHOUDHURI, A. 1987. Mafic dyke swarms of Brasil. In: HALLS, H.C. \& FAHRIG, W.F. eds. Mafic dyke swarms St. John's, Newfoundland, Geol. Assoc. Canada, p.467-481 (Spec. Paper 34)

SIAL, A.N; LONG, L.E.; PESSOA, D.A.R; KAWASHITA, K. 1981. Potassium-argon ages and strontium isotope geochemistry of Mesozoic and Tertiary basaltic rocks, Northeastern Brazil. An. Acad. bras. Ciênc., v. 53, n. 1, p. 115-122.

SILVA, J.M.R.da, LIMA, M.I.C.de; VERONESE, V.F.; RIBEIRO JÚNIOR, R,; SIGA JÚNIOR, O. 1983. Geologia. In: BRASIL, DNPM. Projeto RADAMBRASIL. Folha SE. 24, Rio Doce. Rio de Janeiro: MME/Secretaria Geral. 1983. (Levantamento de Recursos Naturais, 34).

SOUSA, K.G. de. 1993. Tectono-magmaiic periodicity of the southem Brazilian margin and the adjacent Cretaceous magnetic quiet zone in respect to the evolution of the South Atlantic Ocean. Niterói: UFF/LAGEMAR.43p. (Tese, concurso de professor Titular).

STORMER, J.C.; GOMES, C.B.; TORQUATO, R.F. 1975. Spinel lherzolite nodules in basanite lavas from Asunción, Paraguay. Rev. Bras. Geoc., v. 5 , n. 3 ,p. $176-185$.

SUGUIO, K \& PETRI, S. 1973. Stratigraphy of the Iguape-Cananeia lagopnal region sedimentary deposits. São Paulo State, Brasil. Parte 2. Bol. $I G$, n. 4, p. 71-86.

SYKES, L.R. 1978. Intraplate seismicity, reactivation of pre-existing zones of weakness, alkaline magmatism, and other tectonism post-dating continental fragmentation. Rev. Geophys. Spac. Phys., v. 16, n. 4, p. 621-688. 
SZATMARI, P.; FRANÇOLIN, J.B.L.; ZANOTTO, O.; WOLFF, S. 1987. Evolução tectônica da margem equatorial brasileira. Rev. Bras. Geoc., v. 17, n. 2, p. 180-188.

THOMAZ FILHO, A. 1983. Dotação radiométríca de rochas ígneas básicas da bacia do Ceará. Rio de Janeiro: PETROBRÁS/CENPES. (Rel. int. CENPES 673-4462).

THOMAZ FILHO. A, CORDANI, U.G.; KAWASHITA, K. 1976. Aplicação do método $\mathrm{Rb} / \mathrm{Sr}$ na datação de rochas sedimentares argilosas na Bacia do Paraná. In: CONGR. BRAS. GEOL., 29, Ouro Preto, 1976. Anais... São Paulo: SBG. v. 4, p. 289-302.

ULBRICH, H.G.J. 1984. A petrologia, a estrutura e o quimismo de nefelina sienitos do maciço alcalino de Poços de Caldas, MG-SP. Tese Livre-Docência. São Paulo. Inst. Geoc. USP. 446p.

ULBRICH, H.G.J. \& GOMES, C.B. 1981. Alkaline rocks from continental Brazil. Earth. Sci. Rev., v. 17, p. 135-154.

UNTERNHER, P.; CURIE, D.; OLIVET, J.L.; GOSLIN, J. BEUZART, P. 1988. South Atlantic fits and intraplate boundaries in África and South America. Tectonophysics, v. 155, n. 1-4, p. 169-179.
VIEIRA, J.C.; DIAS, J.L.; CATTO, A.J. 1987. Evolução estrutural da fase rifte da Bacia de Campos. In: SEMIN. TECT. PETROBRÁS, 1, Rio de Janeiro, 1987. Atas... Rio de Janeiro: PETROBRÁS. p. 488-500.

VIEIRA, R.A.B.; MENDES, M.P.; VIEIRA, P.E.; COSTA, L.A.R.; TAGLIARI, C.V.; BACELAR, L.A.P. \& FEIJO, F.J. 1994. Bacias do Espírito Santo e Mucuri. Bol. Geoc. Petrobras, v. 8, n. 1, p. 191- 202.

ZALÁN, P.V. \& WARME, J.E. 1985. Tectonics and sedimentation of the Piaui-Camocim Sub-basin, Ceará Basin, Offshore Northeastern Brazil. Rio de Janeiro: PETROBRÁS/CENPES/ DINTEP. 71 p. (Série Ciência-Técnica-Petróleo, 17).

ZALÁN, P.V.; WOLFF, S.; CONCEICCÃO, J.C.J.; MARQUES, A. 1990. Bacia do Paraná. In: GABAGLIA, G.P.R. \& MILANI, E.J. coords. Origem e evolução de bacias sedimentares. Rio de Janeiro: Petrobras. p. $135-168$.

MANUSCRITO $\mathrm{N}^{\circ}$ A802

Recebido em 31 de agosto de 1996

Revisã o dos autores em 19 de fevereiro de 1997 Revisã 0 aceita em 20 de fevereiro de 1997 